\title{
Article
}

\section{Investigation of Science Faculty with Education Specialties within the Largest University System in the United States}

\author{
Seth D. Bush, ${ }^{\dagger *}$ Nancy J. Pelaez, ${ }^{\dagger \dagger}$ James A. Rudd, ${ }^{\dagger \S}$ Michael T. Stevens, ${ }^{+||}$ \\ Kimberly D. Tanner, ${ }^{+4 l}$ and Kathy S. Williams ${ }^{\text {t\# }}$
}

${ }^{*}$ California Polytechnic State University, San Luis Obispo, CA 93407; $¥$ Purdue University, West Lafayette, IN 47907; §California State University, Los Angeles, CA 90032; "Utah Valley University, Orem, UT 84058; ISan Francisco State University, San Francisco, CA 94132; and \#San Diego State University, San Diego, CA 92182

Submitted August 26, 2010; Revised November 22, 2010; Accepted November 23, 2010

Monitoring Editor: Deborah Allen

\begin{abstract}
Efforts to improve science education include university science departments hiring Science Faculty with Education Specialties (SFES), scientists who take on specialized roles in science education within their discipline. Although these positions have existed for decades and may be growing more common, few reports have investigated the SFES approach to improving science education. We present comprehensive data on the SFES in the California State University (CSU) system, the largest university system in the United States. We found that CSU SFES were engaged in three key arenas including K-12 science education, undergraduate science education, and discipline-based science education research. As such, CSU SFES appeared to be well-positioned to have an impact on science education from within science departments. However, there appeared to be a lack of clarity and agreement about the purpose of these SFES positions. In addition, formal training in science education among CSU SFES was limited. Although over 75\% of CSU SFES were fulfilled by their teaching, scholarship, and service, our results revealed that almost $40 \%$ of CSU SFES were seriously considering leaving their positions. Our data suggest that science departments would likely benefit from explicit discussions about the role of SFES and strategies for supporting their professional activities.
\end{abstract}

\section{INTRODUCTION}

In the United States there is strong and growing interest in improving science education (National Academy of Sciences [NAS], 2005; NAS et al., 2007; National Research Council,

DOI: $10.1187 /$ cbe.10-08-0106

${ }^{+}$All authors contributed equally to the research and writing of this article and are listed alphabetically.

Address correspondence to: Michael T. Stevens (michael.stevens@ uvu.edu).

(c) 2011 S. D. Bush et al. CBE-Life Sciences Education (C) 2011 The American Society for Cell Biology. This article is distributed by The American Society for Cell Biology under license from the author(s). It is available to the public under an AttributionNoncommercial-Share Alike 3.0 Unported Creative Commons License (http:/ / creativecommons.org/licenses/by-nc-sa/3.0).

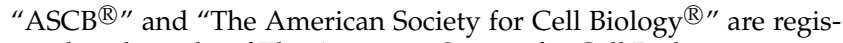
tered trademarks of The American Society for Cell Biology.
2007; National Science Board, 2007; U.S. Congress House of Representatives, 2007). Three arenas in science education are particularly key: 1) the preparation and support of sufficient numbers of quality $\mathrm{K}-12$ science teachers, 2) the improvement of undergraduate science education, and 3) the expansion of the science education research base in specific science disciplines. Most scientists who are situated in a college or university are engaged in undergraduate teaching, either in classrooms or laboratories, and as such are continually called to join in undergraduate science education reform. In addition, the call for scientists to be involved in K-12 science education has been apparent since the 1980s in the following ways: within professional scientific organizations (e.g., American Association for the Advancement of Science, 1993), as part of school university partnership programs (e.g., Alberts, 1994; Bower, 2001; Pelaez and Gonzalez, 2002; Dolan and Tanner, 2005), in the context of graduate training programs (e.g., National Science Foundation [NSF] GK-12), within science departments (e.g., NSF, 1996; McWilliam et al., 
2008; Woodin et al., 2010), and at the level of broader impacts within individual NSF research grants. Basic research scientists are apparently being asked to engage in discussions between the sciences and a range of disciplines informing the field of science education, such as cognitive science, developmental psychology, cultural diversity, and education. However, science faculty largely lack formal training in the teaching and learning of their discipline, deep knowledge of the culture and parameters of $\mathrm{K}-12$ schools, and/or professional incentives to strongly embrace science education. Perhaps unsurprisingly, attempts to involve already busy science faculty in additional science education efforts-outside of their formal training and research focus and without the professional reward structure associated with their basic research efforts-have been challenging and have met with limited impact (Sunal et al., 2001; Walczyk et al., 2007). Compounding the challenges in $\mathrm{K}-12$ and undergraduate science education, there is an additional need for more research on how students learn science within specific science disciplines and on the effectiveness of science teaching strategies in those disciplines at all educational levels.

One emergent approach to stimulating change in all science education arenas is the seeding of university science departments with Science Faculty with Education Specialties (SFES), scientists who take on specialized roles within science education in their discipline (American Physical Society, 1999; Bush et al., 2008, 2010). Although a plethora of innovative curricular and pedagogical approaches to science education have been developed and investigated, the translation and implementation of these findings have been weak (Woodin et al., 2010). Inclusion of a science education specialist in science departments may provide a human bridge between the often isolated efforts in science and in education. SFES appear to be nucleating science education activities on campuses outside of Colleges of Education and may indicate a jurisdictional shift in science education, with science departments explicitly taking on the improvement of science education as part of their charge. The hypothesized impact of SFES includes, but is not limited to, increased articulation between $\mathrm{K}-12$ and undergraduate science education, support for faculty development and nucleation of pedagogical innovation in undergraduate science, and research on teaching and learning specific to a science discipline within that discipline itself. Even though SFES occupy a pivotal role at the interface of key arenas in science education, there has been little formal discussion or systematic investigation of the purposes, structures, or outcomes of these SFES positions or strategies for the hiring, retention, or promotion of SFES (California State University, 2006; Bush et al., 2006, 2008, 2010). As such, SFES appear to be a phenomenon of national interest that is understudied and surrounded by assumptions that are untested.

The investment by science departments in a faculty-level academic position focused on science education-with its accompanying status and intellectual freedom-is substantial and has been described. In 2006, we reported on the challenges associated with hiring SFES (Bush et al., 2006). There we presented a hiring guide for departments interested in SFES and for SFES looking for employment. In 2008, we presented preliminary findings about SFES in the nation's largest university system (annual enrollment $\sim 450,000$ ), the 23-campus California State University (CSU) system. We found that SFES were present throughout the CSU and included two distinct subpopulations: those specifically hired as SFES and those who transitioned to SFES roles from their initial faculty roles (Bush et al., 2008). Strikingly, we found that nearly $40 \%$ of CSU SFES were "seriously considering leaving" their current positions.

Here we more thoroughly report findings from our research on CSU SFES. The CSU's primary mission is undergraduate and master's-level graduate education, including $\mathrm{K}-12$ teacher education. CSU undergraduates come from the top one-third of their high school graduating classes (University of California Office of the President, 2007). The 23 campuses include institutions that differ substantially in their founding dates, settings, student populations, enrollment sizes, and levels of research orientation, and as such our findings are potentially predictive of the characteristics of the SFES model at a variety of institution types.

The purpose of this study was to identify the extent to which SFES exist in the largest university system in the United States, as well as to examine the nature of SFES professional activities and SFES perceptions of their specialized positions. Results are intended to aid a broad audience of stakeholders-including higher education administrators, state and national policy makers, funding agencies, science departments in colleges and universities, and individual scientists considering SFES career pathways-in conceptualizing, structuring, and supporting SFES positions. Results from investigating the CSU SFES phenomenon may prove useful for framing discussions about the purpose of SFES positions, their potential impact on science education from within science departments, and strategies for maximizing the SFES impact.

\section{METHODS}

A survey instrument was designed to collect information about SFES demographics, position structure, and other issues, such as what SFES are doing and perceptions of how SFES positions are structured. In addition, the instrument collected attitudinal information relevant to SFES perceptions of job expectations relative to non-SFES peers, issues of professional satisfaction, pathways to SFES positions, and other information that is primarily of a descriptive nature (e.g., hire date, nature of formal training). SFES professional activities were probed with respect to teaching, scholarly activity, and service since this framework is used in the evaluation of CSU faculty for retention, tenure, and promotion. Although scholarly activity can be broadly defined, use here is in accordance with the CSU definition that includes research, scholarly, and creative activities. As part of face validation, the survey was piloted using non-CSU faculty. Preliminary research results from this study have already been published (Bush et al., 2008). This study constitutes a descriptive study of CSU SFES and is not intended to be a direct comparison of SFES and non-SFES science faculty. However, some survey questions asked SFES to consider their experiences relative to non-SFES in their department.

SFES were identified for this study by 1) soliciting names of potential SFES from CSU College of Science Deans, 2) examining all CSU science department websites in search of SFES profiles, and 3) prompting initial survey respondents to provide names of additional SFES on their campuses. A total 
A)

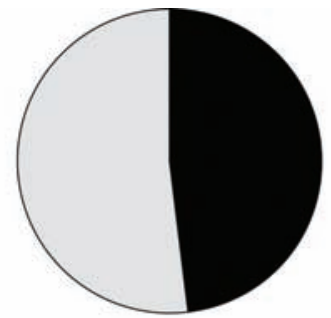

All SFES $(\mathrm{N}=56)$

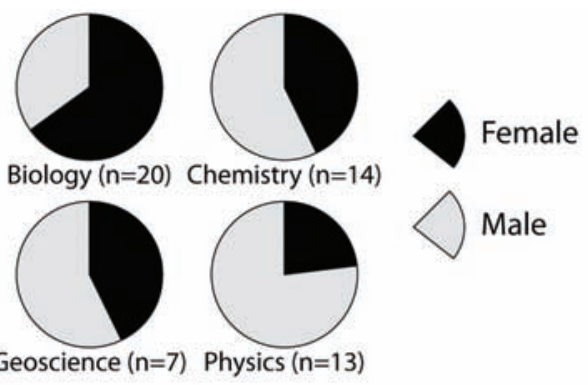

Geoscience $(n=7)$ Physics $(n=13)$

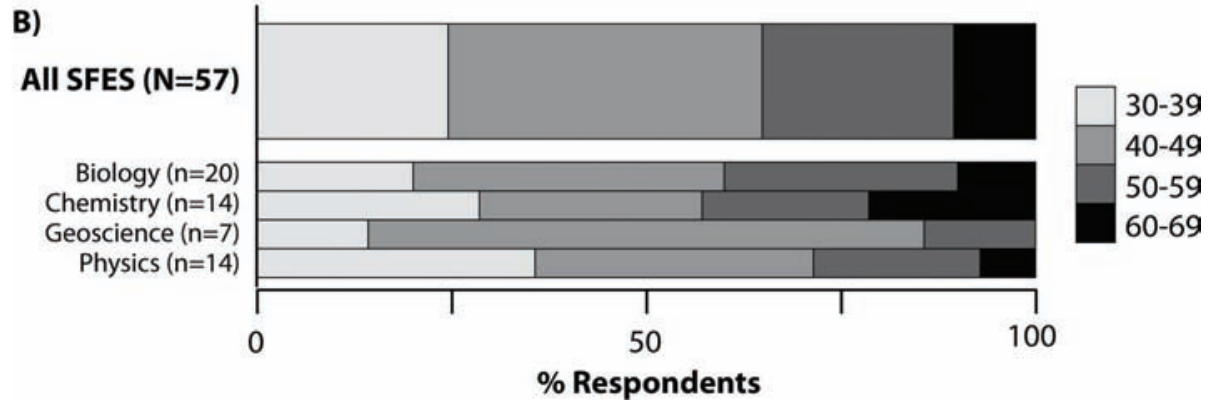

Figure 1. SFES age and gender. Reported gender (A) and age (in years; B) for all SFES and disaggregated by science discipline. of 156 CSU faculty were invited to complete a 111-question, online survey, and 103 of the invitees responded to the survey between December 2007 and January 2008 (66\% response rate). We used snowball sampling. The initial survey respondents provided 66 names of likely SFES, of which only 7 had not yet been invited, suggesting that our SFES search was comprehensive. Research participants represented 20 of the 23 campuses and received a \$20 gift card in compensation for their participation.

Data were collected anonymously, such that individual responses were not associated with a particular CSU campus. Surveys that were incomplete $(n=12)$, not submitted by tenure/tenure-track science faculty $(n=10)$, or lacking informed consent $(n=3)$ were excluded from this analysis. Of the remaining 78 survey respondents, 59 individuals selfidentified as SFES, whereas 19 self-identified as not SFES. Analyses presented in this paper are based on data from the 59 individuals who self-identified as SFES. The only exception appears later in Figure 13, which includes data from the 19 faculty who self-identified as not SFES. In a previous publication of preliminary findings, we excluded individuals located in science education centers from analyses, but in this report, we have included these individuals as part of all SFES. We have not displayed their disaggregated data because of their low number $(n=2)$.

Results from the survey instrument are generally reported as descriptive statistics, and comparisons are not statistically significant unless explicitly stated. When appropriate, Pearson $\chi^{2}$ tests (independence and goodness-of-fit) were used to compare subpopulations of SFES (e.g., Biology SFES versus SFES from other science disciplines, or faculty considering leaving their position versus those intending to stay) and to infer at the $p<0.05$-level that these differences in subpopulations would likely be found at comparable institutions (Plackett, 1983). Yates's correction was used for the $\chi^{2}$ test when the contingency table involved cells with small numbers to prevent overestimation of statistical significance (Yates, 1934).
Open-ended survey questions were analyzed using grounded theory analysis (Glaser and Strauss, 1967). Two researchers examined all responses for each open-ended question, determined emergent themes independently, and then agreed upon a common set of thematic coding categories. Each researcher independently coded responses into these categories and calculated a percentage of respondents who offered evidence in each category. Categories presented in the results are those that included comments coded from more than $10 \%$ of respondents. Interrater reliability (IRR) was calculated by dividing the number of scoring agreements by the total number of scoring decisions. The number of scoring decisions was calculated by multiplying the number of respondents for each question by the number of thematic coding categories.

Although this CSU SFES study provides new and valuable information about SFES, a limitation is that the study was confined to SFES from one U.S. state university system, largely composed of BS- and MS-granting institutions. However, these results can be used as a basis for discussing the assumptions about faculty-level academic positions focused on science education within the science disciplines.

\section{RESULTS}

The results and figures are organized with a description and display of data for all SFES (including Biology, Chemistry, Geoscience, and Physics SFES) followed by disaggregation by discipline department. The disaggregation was provided because of the different histories of the emergence of SFES in each discipline and because we anticipated readers may be interested in SFES in a particular discipline.

\section{Who Are SFES?}

SFES ( $n=59$ respondents) were found in tenure/tenure-track faculty positions in the variety of institution types in the CSU and across a range of science departments, including Biology 


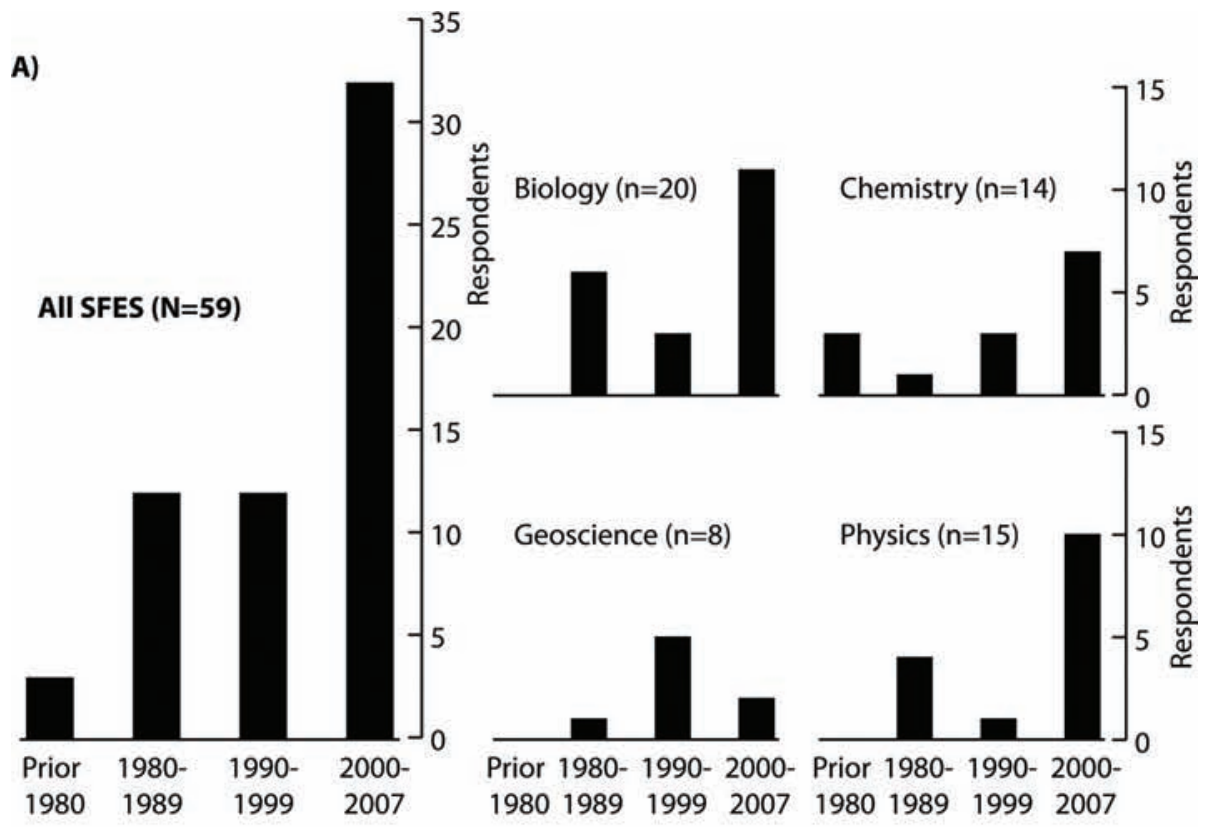

B)

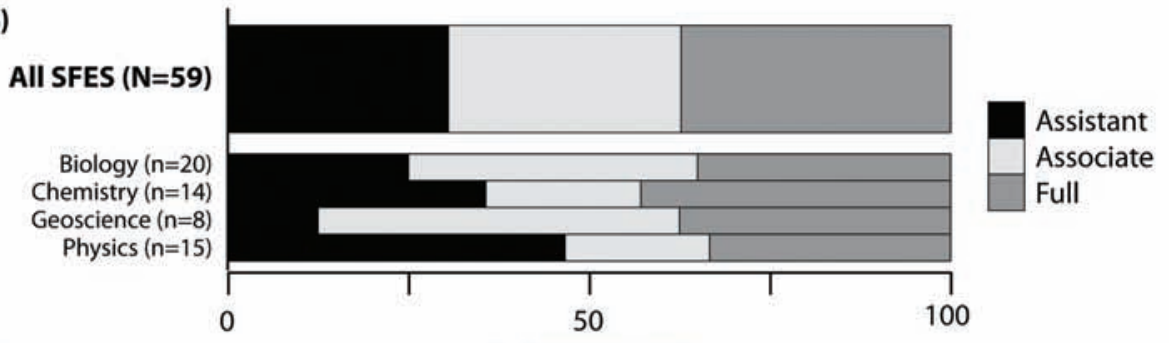

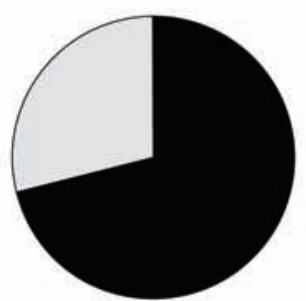

All SFES ( $\mathrm{N}=59)$
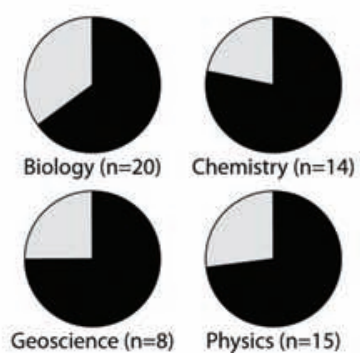

No Tenure Tenure

Figure 2. SFES hire date, rank, and tenure status in relation to SFES status. Reported hire date (A), current rank (B), and tenure status (C) prior to becoming SFES for all SFES and disaggregated by science discipline. $(n=20)$, Chemistry $(n=14)$, Geoscience $(n=8)$, Physics $(n=15)$, and science education centers in Colleges of Science $(n=2)$. In each figure in the Results, the $n$-value represents the actual number of respondents. Roughly equal numbers of female $(48 \%)$ and male $(52 \%)$ SFES responded to our survey. However, there were some differences in gender distributions across departments (Figure 1A). Approximately two-thirds $(65 \%)$ of SFES responding from Biology departments were female, whereas over half of SFES responding from Chemistry, Geoscience, and Physics departments were male (57\%, 57\%, and $77 \%$, respectively). In terms of age distribution, SFES in our study spanned a range of age categories (Figure 1B). The two youngest age categories combined (30-39- and 40-49-yrolds) comprised a majority (65\%) of the overall sample and represented over half of each discipline subsample (Biology $60 \%$, Chemistry 57\%, Geoscience $86 \%$, and Physics $72 \%$ ).
SFES in our study had hire dates from 1970 through 2007 (Figure 2A). The greatest number of SFES were recent hires, hired between 2000 and 2007. This pattern was observed across all departments except Geoscience, where the greatest numbers of SFES were instead hired between 1990 and 1999. SFES represented tenure-track positions across all faculty ranks (31\% assistant, 32\% associate, 37\% full professors; Figure 2B). The proportions of full professors were similar across departments. Biology and Geoscience departments tended to have smaller proportions of assistant professors and higher proportions of associate professors than did Chemistry and Physics departments. The majority (71\%) of SFES as a group did not have tenure when they adopted their roles as SFES (Figure 2C). This pattern was similar across the disciplines (Biology 65\%, Chemistry 79\%, Geoscience 75\%, Physics 73\%). 


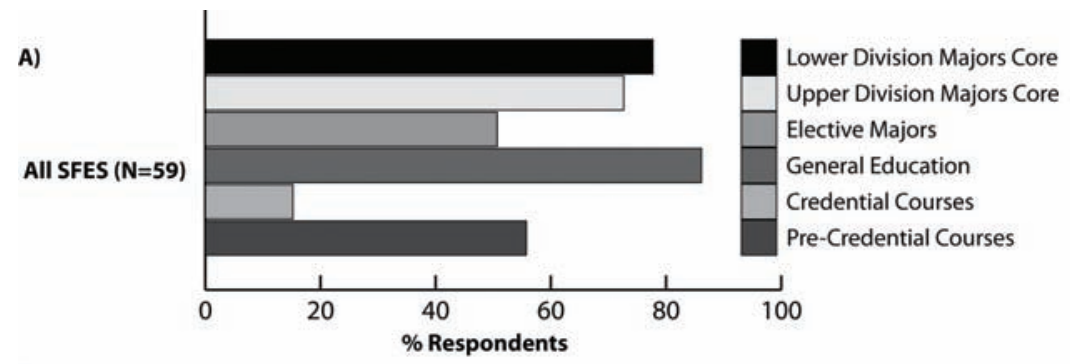

B)

C)

All SFES $(\mathrm{N}=59)$

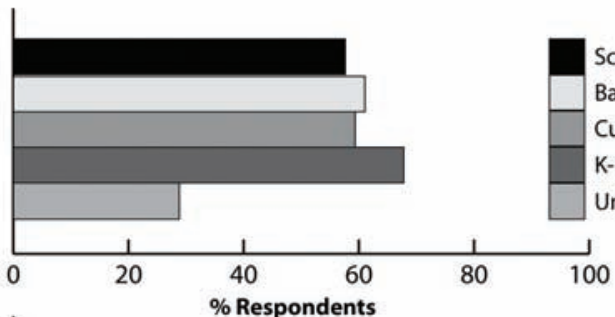

All SFES $(\mathrm{N}=59)$

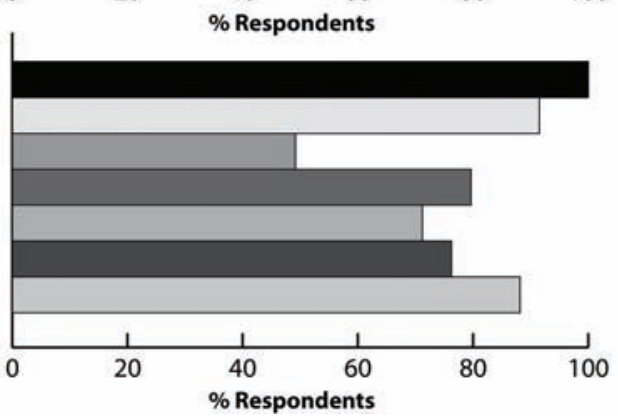

Science Education Research Basic Science Research Curriculum Development K-12 Teacher Development University Teacher Development (1)

\section{Department} College of Science College of Education University Teacher Preparation/Recruitment In-service Teacher support Assessment

\section{What Do SFES Do?}

As a population, SFES appeared to be engaged in a variety of teaching, scholarly, and service activities rather than specializing in one of these areas. With regard to teaching, most SFES in our sample reported teaching courses for majors [lower division (78\%), upper division (73\%), and / or electives (51\%)] and nonmajors (86\%) (Figure 3A). Smaller proportions of SFES (15\%) taught courses for teaching credential students, whereas over $50 \%$ taught precredential courses. As scholars, over half of SFES reported seeking funding to support science education research $(58 \%)$, basic science research (61\%), curriculum development $(59 \%)$, and $\mathrm{K}-12$ teacher development $(68 \%)$ (Figure $3 \mathrm{~B})$. A smaller proportion of SFES reported seeking funding to support university teacher development (29\%). All SFES reported involvement in departmental service with $92 \%$ serving Colleges of Science and $49 \%$ providing service for Colleges of Education (Figure 3C). Typically, the respondents in our sample reported being engaged in service activities for their university (80\%) and in- volved in teacher preparation/recruitment (71\%), in-service teacher support $(76 \%)$, and assessment $(88 \%)$.

SFES in the CSU procured external funding to support their professional activities. Over $40 \%$ of SFES in our sample had garnered more than $\$ 500,000$ in their current position (Figure 4). Over half of Biology and Geoscience SFES had obtained over $\$ 500,000$ in grant funding $(55 \%$ and $63 \%$, respectively), whereas smaller proportions of Chemistry and Physics SFES had procured that level of funding (21\% and $20 \%$, respectively).

SFES activities appeared to reflect their reasons for adopting an SFES role. The survey asked respondents to elaborate on their response choices in several open-ended questions. Table 1 describes six categories of reasons offered by respondents for taking an SFES position $(n=56, \mathrm{IRR}=97 \%)$. The categories that included responses from more than onethird of the respondents were their interest in science education across the three arenas (48\%), specific nature of the faculty position (36\%), and flexibility in balancing teaching and

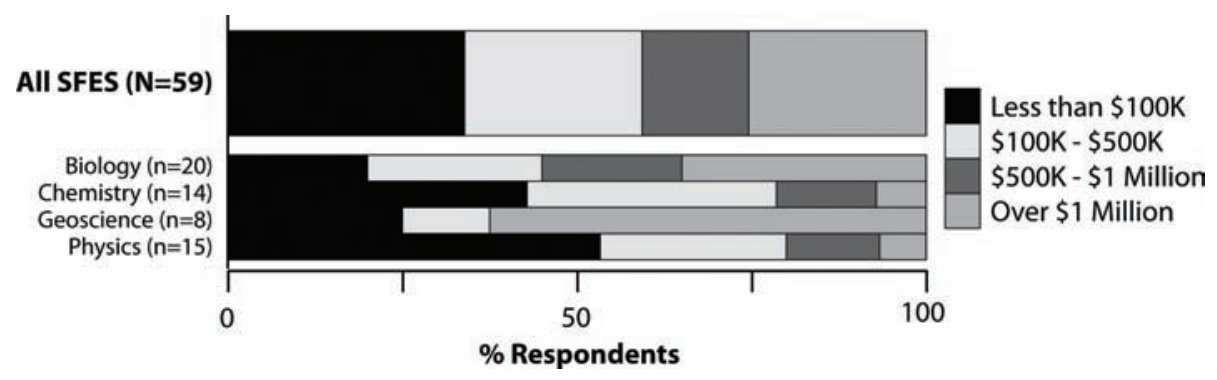

Figure 4. SFES money raised. Total funding raised by all SFES and disaggregated by science discipline. 
Table 1. Reasons for taking an SFES position in response to the following question: "Briefly, what were your original reasons for taking your current position?" $(n=56)$

\begin{tabular}{|c|c|c|}
\hline Category & Sample quotes & $\%$ \\
\hline \multirow[t]{3}{*}{$\begin{array}{l}\text { Interest in science } \\
\text { education }\end{array}$} & $\begin{array}{l}\text { Influencing } K-12 \text { science education } \\
\text { - I was interested and excited about the possibility of teaching teachers (both pre-service and in-service). } \\
\text { - I wanted to positively impact the K-12 education system in the state of California. } \\
\text { - As a new parent, and seeing the state of science education in the country, I felt that it was imperative } \\
\text { that people with backgrounds in science have an impact on the K-12 education process. }\end{array}$ & 48 \\
\hline & $\begin{array}{l}\text { Improving college and university science teaching } \\
\text { - I was excited about the opportunity to become involved in the curricular changes that were planned by } \\
\text { my department, and I had an interest in science education/curricular innovation/ assessment. } \\
\text { - I was interested in trying to encourage reform of university-level science teaching. } \\
\text { - I was excited to join a growing department where I would be able to shape the program development } \\
\text { of the Physics major. }\end{array}$ & \\
\hline & $\begin{array}{l}\text { Engaging in science education research } \\
\text { - Interest in having a laboratory of my own where I could return to conducting science education } \\
\text { research. } \\
\text { - Desire to work in a Chemistry department and conduct research in chemical education. } \\
\text { - Ability to do Physics education-related research. }\end{array}$ & \\
\hline \multirow[t]{3}{*}{$\begin{array}{l}\text { Specific nature of the } \\
\text { faculty position }\end{array}$} & $\begin{array}{l}\text { Geographic location of institution } \\
\text { - I wanted to move my family back to California to be close to grandparents. } \\
\text { - I was looking for a job in this geographical area because of personal reasons. } \\
\text { - Location in California is close to my field area (basic scientific research). }\end{array}$ & 36 \\
\hline & $\begin{array}{l}\text { Characteristics of student population } \\
\text { - I was attracted strongly to working at an institution that serves a large population of ethnic minorities } \\
\text { and first-time college students because of my personal background. } \\
\text { - I wanted to work at a CSU because I am committed to public education and access. }\end{array}$ & \\
\hline & $\begin{array}{l}\text { Reputation of the institution } \\
\text { - The opportunity to teach and engage in research and scholarly activities at my alma mater. } \\
\text { - I already felt a sense of community and ability to relate to the student body. } \\
\text { - I wanted to be affiliated with an excellent institution and department with programs that I respected. }\end{array}$ & \\
\hline $\begin{array}{l}\text { Flexibility in balancing } \\
\text { teaching and } \\
\text { research }\end{array}$ & $\begin{array}{l}\text { - I wanted a university position that was an even balance of teaching and research. The available } \\
\text { position at this university offered that compromise. } \\
\text { - The position melded all my areas of expertise, genetics, teaching, science education, etc. } \\
\text { - I was interested in doing science teaching and research where both would be valued. }\end{array}$ & 36 \\
\hline $\begin{array}{l}\text { Desire to teach at the } \\
\text { undergraduate level }\end{array}$ & $\begin{array}{l}\text { - After teaching at the high school level for several years, I wanted to teach at the university level. } \\
\text { - The reason I took my position in the first place was that I wanted to teach undergraduate science. } \\
\text { - I love science and wanted to transmit my passion for it through teaching. } \\
\text { - I wanted to change the way students think about the world around them, teaching, and learning. }\end{array}$ & 23 \\
\hline $\begin{array}{l}\text { Collegial environment, } \\
\text { sometimes including } \\
\text { presence of other } \\
\text { SFES }\end{array}$ & $\begin{array}{l}\text { - Attracted to the collegial nature of faculty in my department and college. } \\
\text { - Having another SFES faculty member in the department (and others across the college) was another } \\
\text { important consideration. } \\
\text { - [The institution] offered a strong, collegial department with a commitment to teaching, basic research, } \\
\text { and K-12 teacher prep that allows me to pursue all my interests quite freely. } \\
\text { - It was rare to find a place that said that the science education specialist (SFES) would be treated just like } \\
\text { a non-SFES in terms of research, teaching, and service. }\end{array}$ & 18 \\
\hline $\begin{array}{l}\text { Need for a job or more } \\
\text { job security }\end{array}$ & $\begin{array}{l}\text { - I really needed a job!... I viewed it as an opportunity to obtain tenure, without having to uproot my } \\
\text { family. } \\
\text { - I was employed here as a lecturer and wanted a more stable position. ... and the security a tenure track } \\
\text { position carried with it that I didn't have as a Lecturer. }\end{array}$ & 11 \\
\hline
\end{tabular}

research (36\%). Additional reasons included a desire to teach at the undergraduate level (23\%), the presence of a collegial environment, sometimes including other SFES $(18 \%)$, or simply a need for a job or more job security $(11 \%)$.

\section{What Is Their Professional Training?}

Virtually all SFES in all disciplines had formal training in science (including postdocs, PhDs, and/or master's degrees) prior to being hired into their current positions (Figure 5, A and B). All Geoscience and Physics SFES had formal training in science, whereas small percentages of Biology and Chemistry SFES did not ( $5 \%$ and $7 \%$, respectively). Most SFES over all disciplines $(88 \%)$ had earned science PhDs, whereas many had completed science postdocs (37\%) and/or science master's degrees (48\%). The patterns of formal training across the disciplines were similar.

In stark contrast, only $32 \%$ of SFES overall reported having any type of formal postbaccalaureate training in science education (Figure 5C). Chemistry SFES had the greatest (43\%) proportion of faculty with any formal science education training; proportions for Biology (30\%), Geoscience (25\%), and 


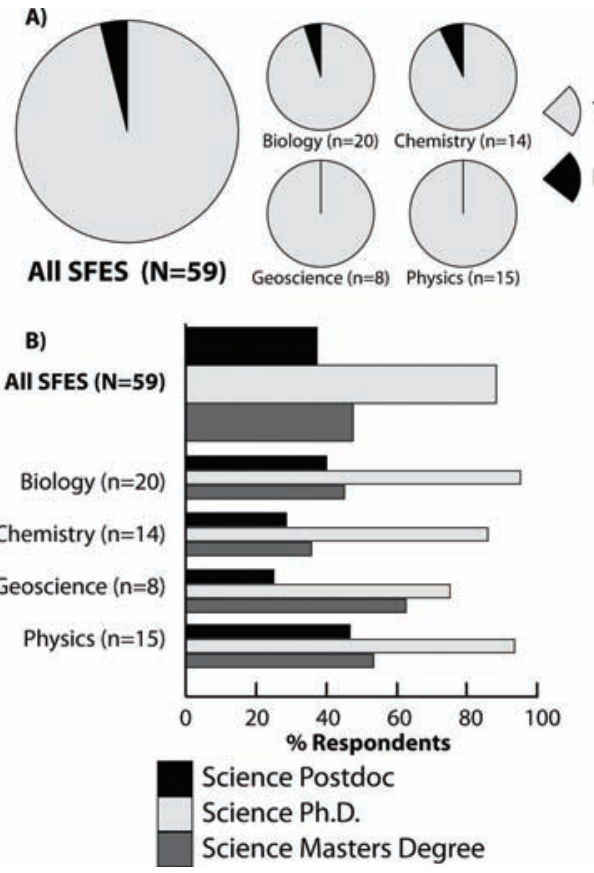

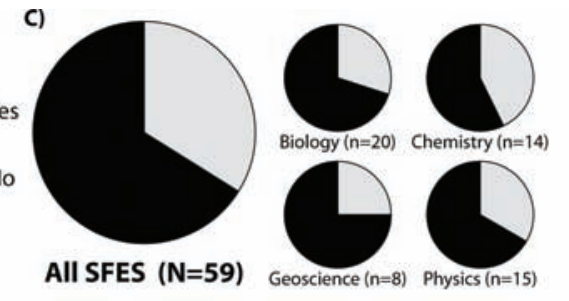

D)

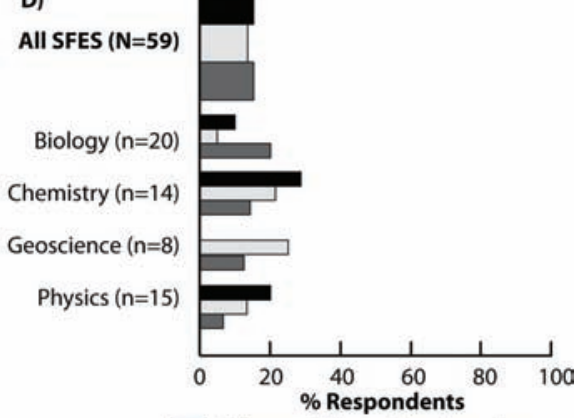

Science Education Postdoc Science Education Ph.D.

K-12 Teaching Credential
Figure 5. SFES professional training. Pie graphs describe the proportions of SFES with any formal postbaccalaureate training in science (A) and science education (C). Bar graphs describe the types of formal postbaccalaureate training SFES report in science (B) and science education (D) for all SFES and disaggregated by science discipline.

A) Perception of Teaching

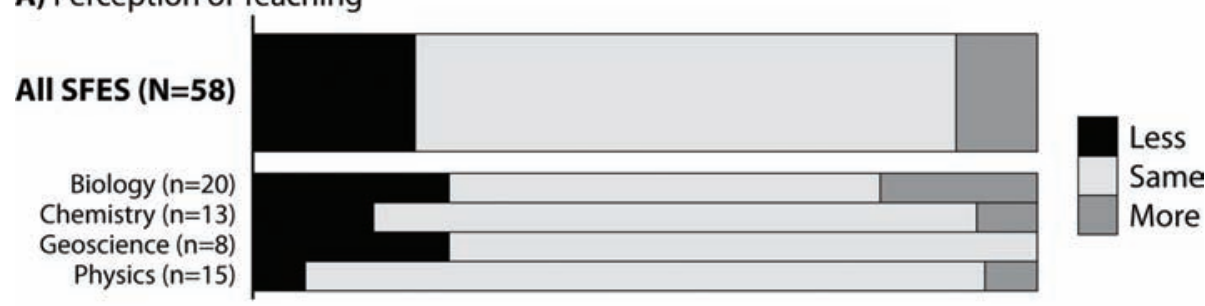

\section{B) Perception of Scholarship}

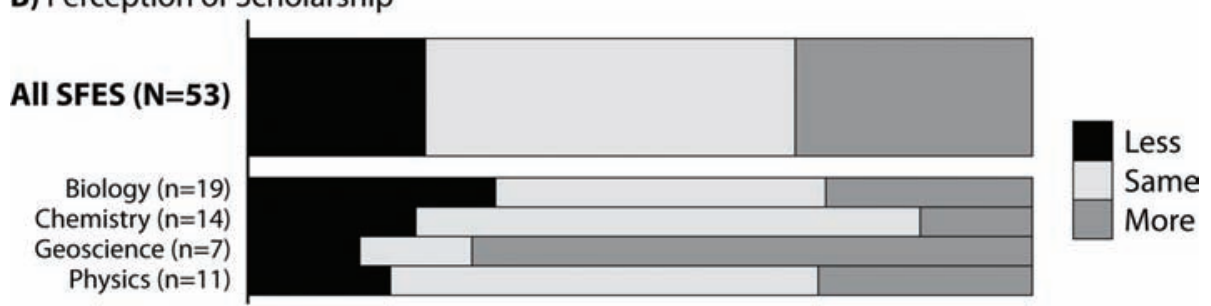

C) Perception of Service

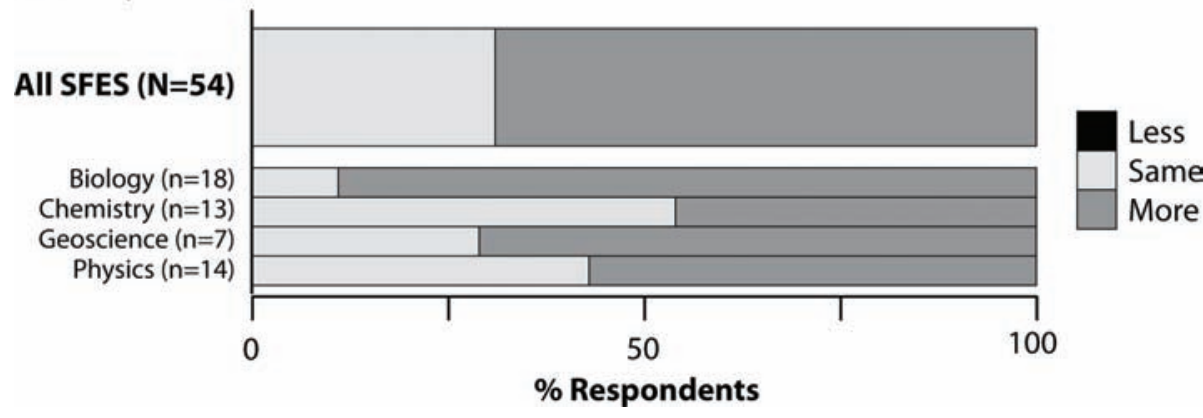

Figure 6. SFES perceptions of time spent on professional activities compared with non-SFES. Perceptions of teaching (A), scholarship (B), and service (C) relative to non-SFES for all SFES and disaggregated by science discipline. 

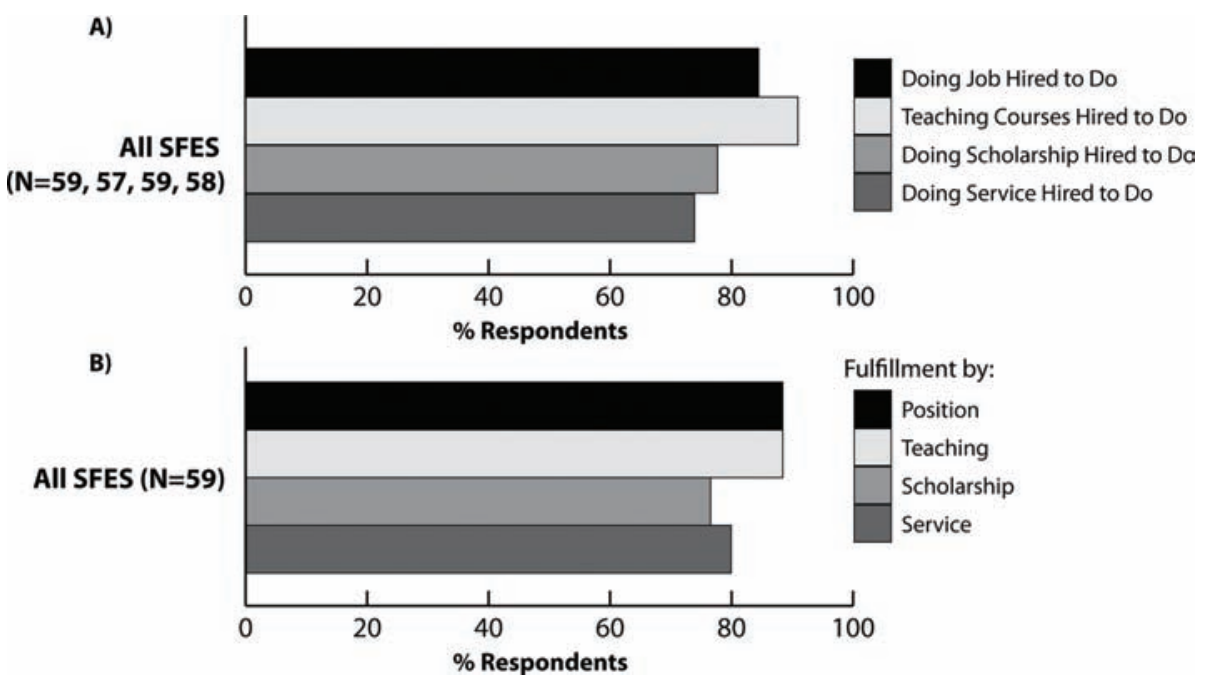

Figure 7. SFES professional fulfillment and position expectations. (A) Percentages of SFES reporting that they are doing the job, teaching, scholarship, and service they were hired to do. (B) Percentages of SFES reporting that they are fulfilled by their position, teaching, scholarship, and service.

Physics (27\%) were lower. The patterns of the types of formal training in science education varied among disciplines (Figure 5D). For example, 20\% of Biology SFES had earned teaching credentials, $10 \%$ had conducted postdoctoral work in science education, and only $5 \%$ had earned science education doctorates. SFES in both Chemistry (29\%) and Physics $(20 \%)$ showed relatively large proportions with science education postdoctoral experiences, smaller proportions with science education doctoral degrees $(21 \%$ and $13 \%$, respectively), and even smaller proportions with teaching credentials $(14 \%$ and $7 \%$, respectively). In the small sample of Geoscience SFES, $25 \%$ held science education doctorates, $13 \%$ had teaching credentials, and none had postdoctoral experience in science education.

\section{Perceptions of Activities and Professional Satisfaction}

Given the many contributions SFES could make to science education, it is worth noting how SFES perceived the demands on their time for teaching, scholarly activities, and service (Figure 6). A large proportion of SFES in our sample $(69 \%)$ reported spending "about the same" time on teaching as non-SFES. From here forward, we define non-SFES as other science faculty in the same department who are not specializing in science education. In terms of scholarly activities, there was less agreement about whether they spent "more" (30\%), "about the same" (47\%), or "less" (23\%) time on their scholarly activities compared with non-SFES (Figure 6B). Though the sample size was small $(n=7)$, over $70 \%$ of Geoscience SFES reported spending more time on scholarly activities than their non-SFES Geoscience colleagues, whereas proportions for Biology $(26 \%)$, Chemistry $(14 \%)$, and Physics $(27 \%)$ were lower. Regarding service activities, SFES across all disciplines (69\%) perceived spending more time on service than non-SFES (Figure 6C) with none reporting less time spent on service. The extreme was represented by Biology SFES, with $89 \%$ reporting that they perceived spending more time on service activities than their non-SFES Biology colleagues. SFES perceived their department and college service activities as being similar to that of non-SFES. At least $50 \%$ of SFES re- ported having specific responsibilities in $\mathrm{K}-12$ teacher preparation, K-12 teacher professional development, and other College of Education collaborations (Figure 3). SFES reported that these additional activities were not expected of non-SFES.

Although SFES were engaged in diverse activities in their positions (Figure 3), there was a high level of agreement among SFES that they were doing the job they were hired to do (Figure 7A). In addition, levels of fulfillment among SFES were very high with regard to their SFES position in general (Figure 7B), with more than $75 \%$ reporting being fulfilled by each of these activities.

That fulfillment appeared to be reflected in SFES responses to open-ended questions. Table 2 describes the reasons offered by respondents for continuing to stay in their SFES position $(n=52, \mathrm{IRR}=96 \%)$. Half of the SFES who responded reported that they remain in their position because they enjoy the challenge, freedom, and activities of their position. In addition, over one-third of SFES respondents expressed that they stayed because they valued relationships with colleagues and collaborators, including other SFES (37\%) and/or they perceived that they were making improvements in science education (35\%). Finally, SFES valued their impact on and relationship with students (25\%), enjoyed teaching $(19 \%)$, and/or were geographically tied to their position $(15 \%)$.

\section{Perceptions of Support and Access to Resources}

Although SFES participated in a great variety of scholarly activities (Figure 3), many consistently perceived a lack of institutional support for those activities, as compared with the support they perceived non-SFES received. Most SFES felt their starting and current salaries were similar to those of non-SFES (Figure 8, A and B) but many SFES reported that, upon hiring, they perceived that they received less start-up funding and less laboratory space compared with non-SFES (45\% and 53\%, respectively; Figure $8, \mathrm{C}$ and D). In addition, most $(78 \%)$ SFES with departmental graduate programs reported having less access to graduate student researchers to support their scholarly activities as compared with non-SFES (Figure 8E). 
Table 2. Reasons offered for staying in SFES position in response to the following question: "Briefly, what are the primary reasons you continue to stay in your current position?" $(n=52)$

\begin{tabular}{|c|c|c|}
\hline Category & Sample quotes & $\%$ \\
\hline $\begin{array}{l}\text { Enjoy the challenge, } \\
\text { freedom, and } \\
\text { activities of } \\
\text { position }\end{array}$ & $\begin{array}{l}\text { - It is important, valuable, and exciting work. } \\
\text { - I couldn't imagine doing anything else. } \\
\text { - I really like what I am doing. } \\
\text { - I love being a pioneer, building a science education research lab, and trying to genuinely } \\
\text { make a change in university-level thinking about science and science teaching. } \\
\text { - I like the flexibility of being able to concentrate on many different things, to grow in my } \\
\text { position in ways I want. }\end{array}$ & 50 \\
\hline $\begin{array}{l}\text { Value relationships } \\
\text { with colleagues and } \\
\text { collaborators, } \\
\text { including other SFES }\end{array}$ & $\begin{array}{l}\text { - I also have been part of a team that works hard to integrate content with pedagogy, and I } \\
\text { think our passion has helped us persevere. } \\
\text { - I feel fortunate to have been a part of a department faculty and college that have been } \\
\text { entirely supportive of my many nontraditional professional activities. } \\
\text { - Other SFES faculty in department and college-excellent colleagues. } \\
\text { - Department collegiality is also pretty good here. }\end{array}$ & 37 \\
\hline $\begin{array}{l}\text { Perceive that they } \\
\text { are making } \\
\text { improvements in } \\
\text { science education }\end{array}$ & $\begin{array}{l}\text { - To help bring about the changes that have been needed for decades. } \\
\text { - It is very encouraging to see progress being made... I want to change the way people } \\
\text { think about teaching and learning of science. } \\
\text { - If we don't change the way we think, we will get more of the same. } \\
\text { - I believe I am making a difference at both the local and national level with respect to } \\
\text { improving science literacy. }\end{array}$ & 35 \\
\hline $\begin{array}{l}\text { Value impact on and } \\
\text { relationships with } \\
\text { students }\end{array}$ & $\begin{array}{l}\text { - I feel that I am making a real difference for the students... I've been able to introduce } \\
\text { some students to research who never thought they were capable, and watching them } \\
\text { blossom as scientists is very rewarding. } \\
\text { - I enjoy... the opportunity to make a difference in the lives of students' futures. }\end{array}$ & 25 \\
\hline Enjoy teaching & $\begin{array}{l}\text { - I am so fortunate to be able to teach and stay engaged with the subject matter that I find } \\
\text { fascinating. } \\
\text { - I really like teaching; I like to see light bulbs go off when they understand something }\end{array}$ & 19 \\
\hline $\begin{array}{l}\text { Are geographically } \\
\text { tied to the } \\
\text { position }\end{array}$ & $\begin{array}{l}\text { - To be honest, a large issue is that my family has settled in to the local community, and I'd } \\
\text { rather not uproot us at this point. } \\
\text { - I love where I live (location, neighbors, friends). }\end{array}$ & 15 \\
\hline
\end{tabular}

Consistent with the perception of less access to resources, generally fewer than $25 \%$ of SFES reported being members of science departments with an academic infrastructureincluding undergraduate or graduate courses and degree programs in science education-equivalent to that available for basic science training (Figure 9). For example, fewer than $10 \%$ of SFES had access to programs offering courses or degrees in science education research for either undergraduate or graduate students (Figure 9, A and B). Generally less than $25 \%$ of SFES reported having access to programs offering undergraduate courses or degree programs in science teaching, and this result was consistent across all science disciplines (Figure 9A). SFES as a group reported even less access to graduate programs and courses in science education research or science teaching (Figure 9B).

\section{Biology SFES Perceptions of Service Demands}

SFES commonly reported that they had greater demands on their time for service activities compared with non-SFES (Figure 6C). A notable difference appeared for Biology SFES, who consistently reported that their efforts were not valued or understood by their university to a degree not seen across other disciplines examined. Smaller proportions of Biology SFES felt that those service activities were understood by their department than did non-Biology SFES (Figure 10A; $\chi^{2}=4.4$, $p=0.036$ ). Similarly, smaller proportions of Biology SFES felt that their service expectations matched those of their uni- versity when compared with non-Biology SFES (Figure 10B; $\left.\chi^{2}=5.4, p=0.020\right)$. That pattern was similar for the perceptions of value for their service activities (Figure 10C).

\section{Comparison of Perceptions between SFES Who Are and Are Not Seriously Considering Leaving Positions}

Almost $40 \%$ of SFES surveyed were seriously considering leaving their current job. Statistical analyses $\left(\chi^{2}\right.$ goodnessof-fit) indicated differences between "Stayers," SFES who were not "seriously considering leaving" their particular position, and "Leavers," SFES who were "seriously considering leaving" their positions. The terms are merely labels, which may or may not reflect reality; Stayers may choose to leave their positions, whereas Leavers may in fact remain in their positions. The largest differences reflected perceived discrepancies in time spent performing professional activities and access to various academic resources that would help them accomplish those activities, as compared with non-SFES. Recognizing that SFES generally perceived having greater demands on their time for service activities (Figure 6C), almost half $(47 \%)$ of the Stayers felt they were spending about the same time on service activities, whereas only $11 \%$ of Leavers felt that way (Figure 11A; $\chi^{2}=7.1, p=0.008$ ). Regarding starting salaries, $87 \%$ of the Stayers reported their perceptions of starting with similar or even larger starting salaries as non-SFES in their department, compared with only $58 \%$ of Leavers reporting starting with similar or even larger 


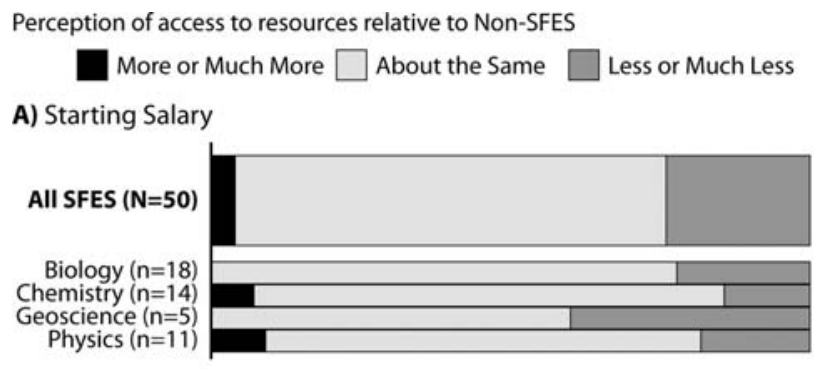

B) Current Salary
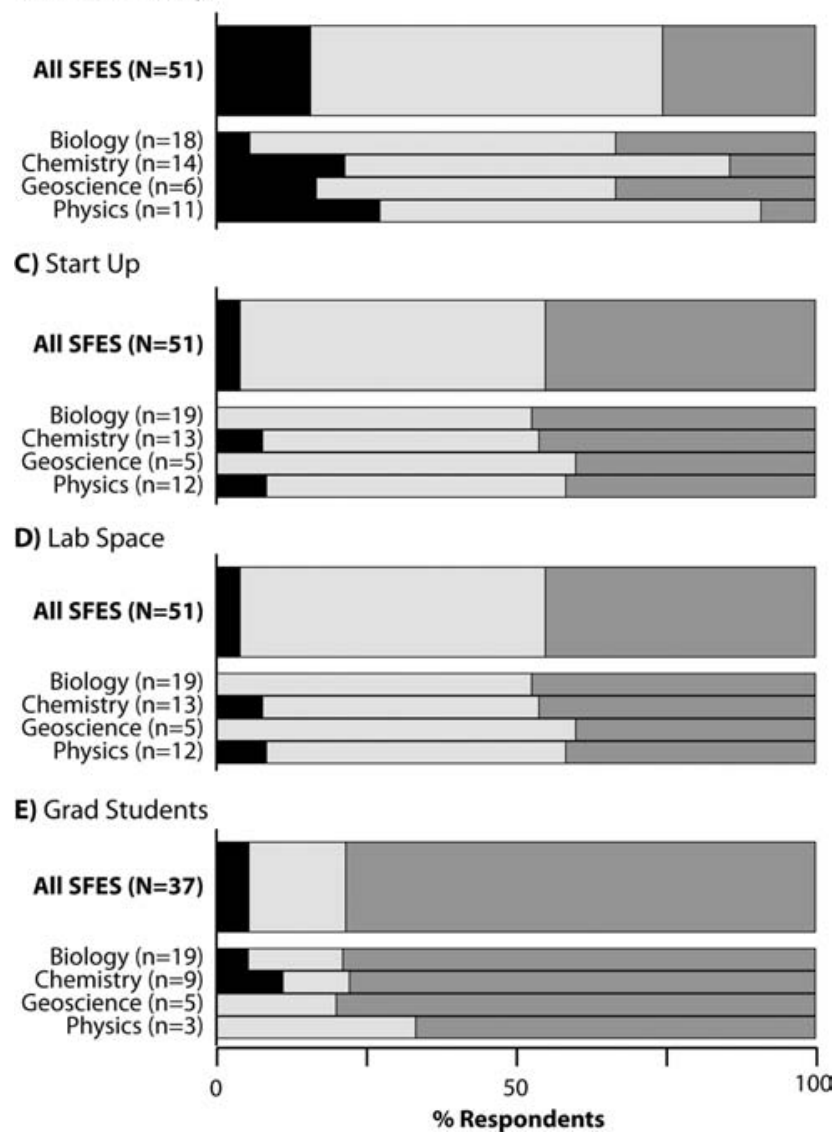

Figure 8. SFES perceptions of access to resources compared with non-SFES. Reported relative starting salary (A), current salary (B), start-up package (C), lab space (D), and access to graduate students (for SFES in departments with graduate programs; E) for all SFES and disaggregated by science discipline.

starting salaries than non-SFES (Figure 11B; $\chi^{2}=5.0, p$ $=0.026)$. Perceived current salaries followed the same trend, with $82 \%$ of Stayers reporting salaries similar to or greater than those of non-SFES in their department, whereas less than half as many Leavers (40\%) perceived having salaries similar to or greater than non-SFES (Figure $\left.11 \mathrm{~B} ; \chi^{2}=9.9, p=0.002\right)$. Compared with Stayers, a higher proportion of Leavers perceived their start-up packages were less or much less than those of non-SFES (Figure $\left.11 \mathrm{~B} ; \chi^{2}=10.5, p=0.001\right)$. Finally, regarding levels of academic freedom for developing research projects, less than $3 \%$ of Stayers perceived limitations to their aca- demic freedom relative to non-SFES, whereas $20 \%$ of Leavers perceived having less academic freedom than non-SFES (Figure 11B).

SFES who self-identified as Stayers and Leavers also differed in their perceptions of their positions (Figure 12, A and C) and professional fulfillment related to their activities (Figure 12B). Compared with Leavers, a higher proportion of Stayers perceived that their overall job expectations were similar to expectations for non-SFES (Figure 12A; $\chi^{2}=8.2, p$ $=0.004$ ). Looking at specific professional activities, only $9 \%$ of Stayers felt that their teaching expectations were different from those of non-SFES, whereas $40 \%$ of Leavers held that perception (Figure 12A; $\chi^{2}=5.7, p=0.017$ ). Similarly, only $6 \%$ of Stayers felt that their scholarly expectations were different than those of non-SFES, whereas 35\% of Leavers held that perception (Figure 12A; $\chi^{2}=5.5, p=0.019$ ). Another discrepancy was seen in the perception of service expectations, with only $38 \%$ of Stayers perceiving that the service expectations placed on them were different from those placed on their non-SFES peers, whereas $79 \%$ of Leavers had that perception (Figure 12A; $\chi^{2}=6.6, p=0.010$ ). Regarding service activities, $91 \%$ of Stayers but only $70 \%$ of Leavers reported being fulfilled by those activities (Figure 12B; $\chi^{2}=2.9, p=$ 0.091). Finally, when comparing perceptions of whether they were doing the job they were hired to do, fully $97 \%$ of Stayers reported that they felt they were doing the job they were hired to do, whereas only $75 \%$ of Leavers shared that perception (Figure 12C; $\chi^{2}=4.5, p=0.034$ ).

Reasons for considering leaving were offered by the subset of respondents who agreed that they were seriously considering leaving their current SFES position $(n=20$ Leavers, IRR $=98 \%$ ) and are described in nine categories in Table 3. The most prevalent reason for seriously considering leaving cited by SFES Leavers was that science education was not supported, valued, or understood by their department and/or university (35\%). In addition, SFES Leavers offered experiences of being overworked, burned out, and underappreciated $(25 \%)$, of feeling that their professional values were not aligned with their department or university $(25 \%)$, and generally feeling that they were not doing what they wanted to be doing (20\%). Some Leavers cited issues related to resources-including salaries that were too low (20\%) and a lack of resources to support scholarly activities in science education (15\%), as well as issues related to workload, including teaching loads (20\%) and service loads (15\%) that were too high. Finally, 35\% of Leavers offered a variety of other reasons for seriously considering leaving that did not fit into the previous categories.

\section{SFES Self-Identification and Pathways}

Of our total survey respondents $(n=78), 25 \%$ did not identify themselves as SFES ("Non-Identifiers"; Figure 13). Higher proportions of chemists and physicists identified themselves as SFES than did biologists and geoscientists. Of those who did identify as SFES, there were two apparent pathways to becoming an SFES: those who were "Hired" as SFES and those who "Transitioned" to SFES roles from their initial faculty roles (Figure 13). Of these faculty, over half of Biology (65\%) and Chemistry (64\%) SFES indicated that they were hired as SFES, and $40 \%$ of Physics and $38 \%$ of Geoscience SFES reported being hired as SFES. The remaining individuals in 
A)

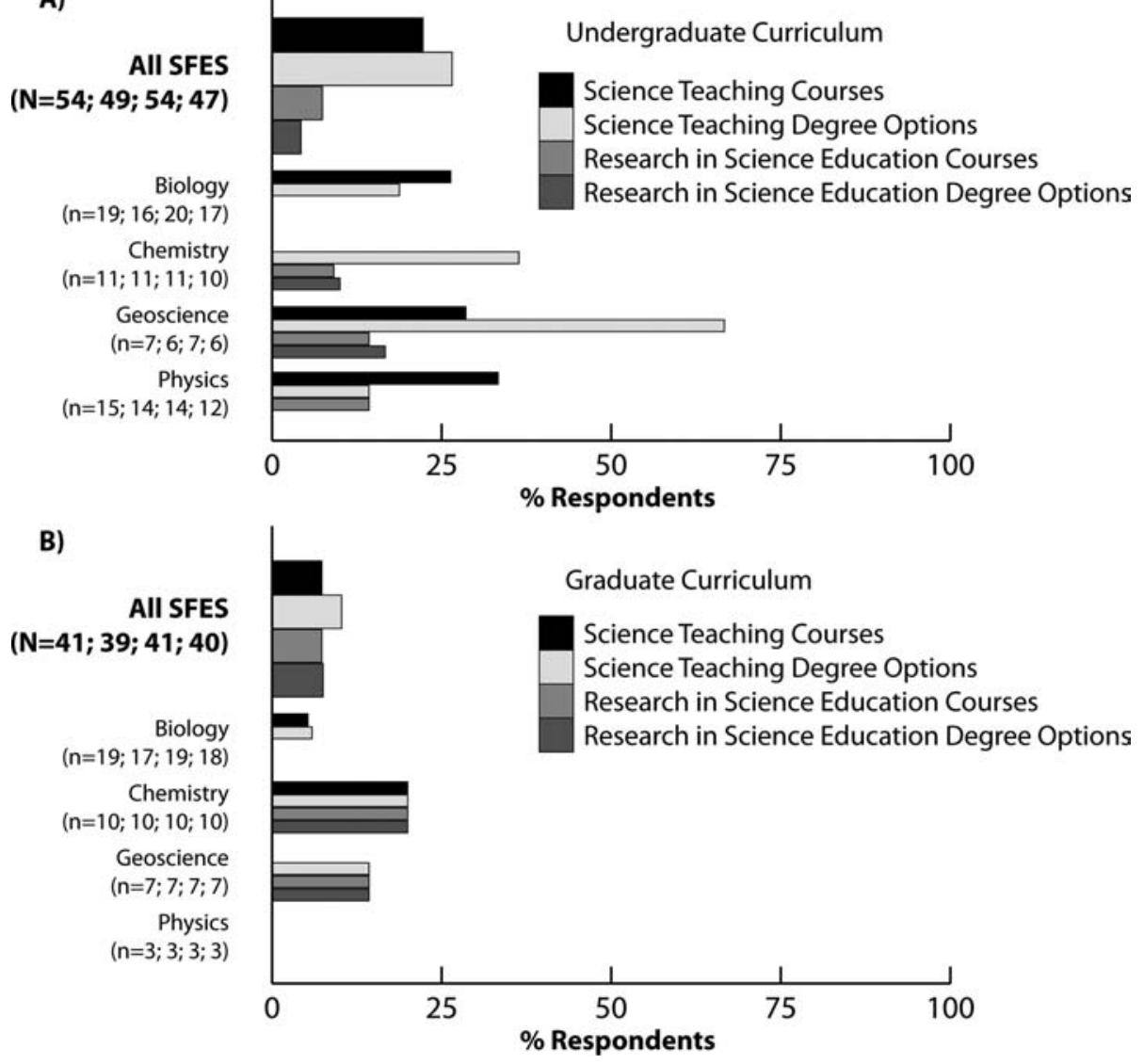

Figure 9. Academic infrastructure for SFES scholarship in science education. Reported undergraduate curriculum elements comparable to basic science (A) and graduate curriculum elements comparable to basic science (B) for all SFES and disaggregated by science discipline. each discipline department transitioned to SFES roles from their initial faculty roles.

\section{SFES Advice about Beginning SFES Positions}

SFES were asked to offer advice to beginning SFES. Table 4 describes nine categories of advice offered by respondents for beginning SFES $(n=50, \operatorname{IRR}=97 \%)$. The most prevalent pieces of advice offered by SFES to beginning SFES were to obtain clear position expectations from their department and college (44\%) and to find colleagues, mentors, and advocates both within and outside their institution (42\%). In addition, SFES respondents encouraged others to obtain funding for and publish their work $(28 \%)$ and reduce their commitments and learn to say no (28\%). Finally, several categories of advice offered strategies for navigating SFES positions, such as informing, educating, and highlighting your efforts among stakeholders at your institution (18\%); making sure that your department and college value and reward science education activities (16\%); and expecting to be treated equitably and just like non-SFES. Finally, having a thick skin and remaining confident and passionate about your work (18\%) and having a clear vision of your professional interests $(10 \%)$ were advised.

\section{DISCUSSION}

This research study represents the first systematic collection and analysis of data on the nature of SFES positions, the individuals who occupy these positions, and the state of sat- isfaction of these individuals with their positions. Results show that SFES positions exist across all science disciplines studied, across all faculty ranks, and at all CSU campuses represented in the study. Thus, the CSU SFES phenomenon is concentrated neither in a single discipline nor on a subset of campuses. Although CSU SFES appear to have been hired into such positions since 1970, more SFES have been hired since 2000 than in the cumulative history of SFES, which is consistent with either a recent expansion of the CSU SFES phenomenon or a long history of SFES hiring and simultaneous attrition.

Although many assume that SFES positions can potentially influence science education in a variety of ways, the SFES phenomenon appears also to have significant challenges. Results from this study suggest that there may be lack of clarity about the role of SFES positions within science departments. In addition, data reveal that $90 \%$ of CSU SFES have formal training in science and only $32 \%$ have formal training in science education. Results describe motivations for taking an SFES position as well as potential issues that may prompt almost $40 \%$ of SFES to seriously considering leaving their position. Although these results are an intriguing profile of CSU SFES, a national study of SFES is needed to investigate the nature and impact of the SFES phenomenon more broadly and to understand how this phenomenon may or may not vary across science disciplines and academic institutions. The results of this research may have implications for individual SFES and also for college and university science administrators hiring them, policy makers and funding agencies, and 
A) Service understood by

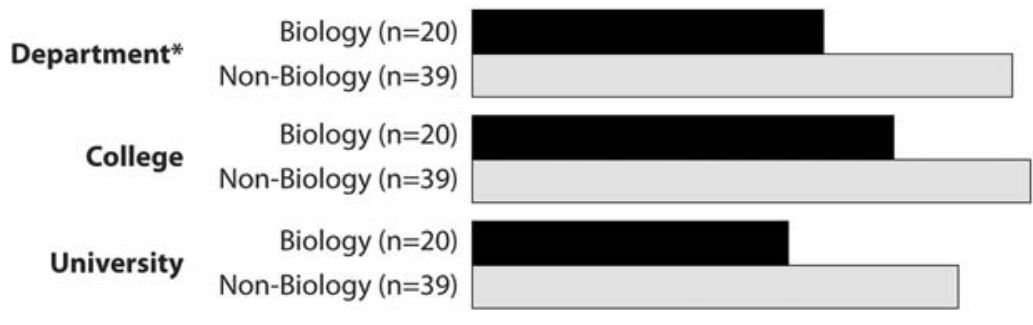

B) Service expectations match

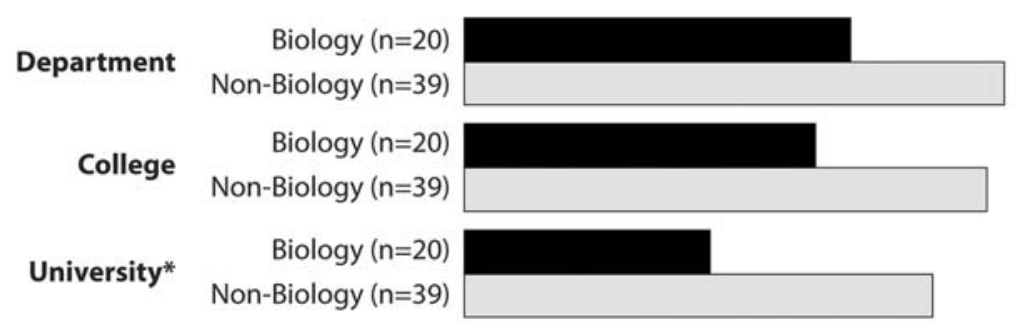

C) Service valued by

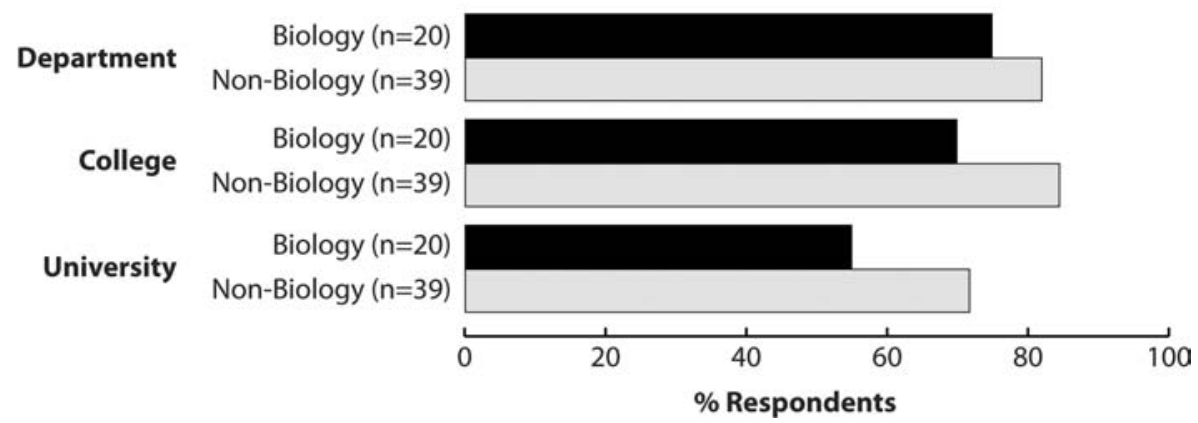

Figure 10. Biology SFES versus nonBiology SFES perceptions of service activities. Perception that SFES service activities are understood by (A), match expectations of $(B)$, and are valued by $(\mathrm{C})$ SFES's department, college, and university disaggregated by Biology SFES and non-Biology SFES. *Indicates statistically significant differences $(p<0.05)$.
non-SFES attempting to understand, support, and evaluate the efforts of SFES.

\section{Lack of Clarity about the Role of SFES Positions within Science Departments}

There appears to be a lack of clarity about the purpose of SFES positions, both in terms of the academic community's general perceptions of SFES and more specifically among SFES and stakeholders at their institutions. In the academic community, multiple ideas about the purpose of SFES positions have been expressed informally. Some may perceive that SFES positions are primarily teaching positions within science departments. Our results do not appear to support this idea, because CSU SFES report teaching about the same amount as their non-SFES peers and a majority are engaged in multiple areas of scholarship. Similarly, others may assume that SFES positions are typically introductory course instructor and/or coordinator positions within science departments. However, CSU SFES were teaching courses that span general education through electives for science majors, as well as precredential and credential courses for teaching majors. Finally, others might consider that SFES positions are designed as science education research positions within science departments. Our results, however, do not support this perception either. Approximately the same proportion of CSU SFES reported being engaged in science education research $(58 \%)$ as reported being engaged in basic science research $(61 \%)$. As such, our data do not support any singular perception of the purpose of an SFES position, suggesting that there are a variety of different conceptualizations of these positions operating within the CSU and perhaps across the country.

In addition, several lines of evidence from this study suggest a lack of clarity between SFES and stakeholders at their institutions about the role of SFES within science departments. In fact, some potential CSU SFES chose to reject identification as SFES, despite being identified as such by their administrators. Of note, the most prevalent piece of advice offered by study respondents to beginning SFES was to obtain clear position expectations in writing from department and college administrators. The highly varied nature of SFES professional activities is perhaps evidence that the purpose of SFES within individual departments was not explicitly articulated, possibly leading to SFES engaging in a broader set of professional activities than they may have envisioned upon being hired. In particular, SFES indicated that they perceived both a lack of understanding of SFES 
A) Perception of time spent on professional activities relative to Non-SFES

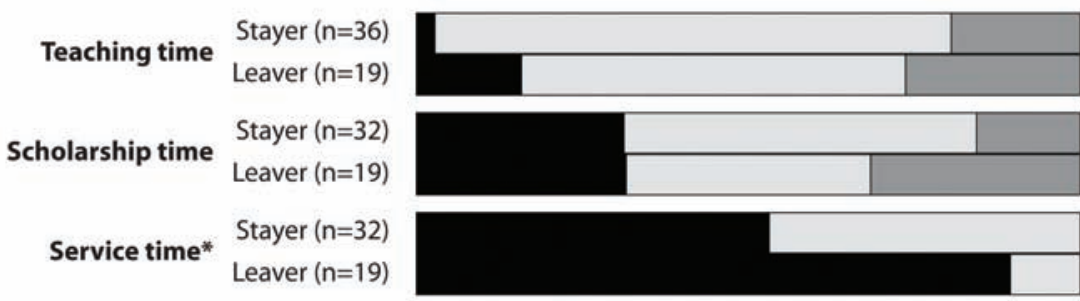

B) Perception of access to resources relative to Non-SFES

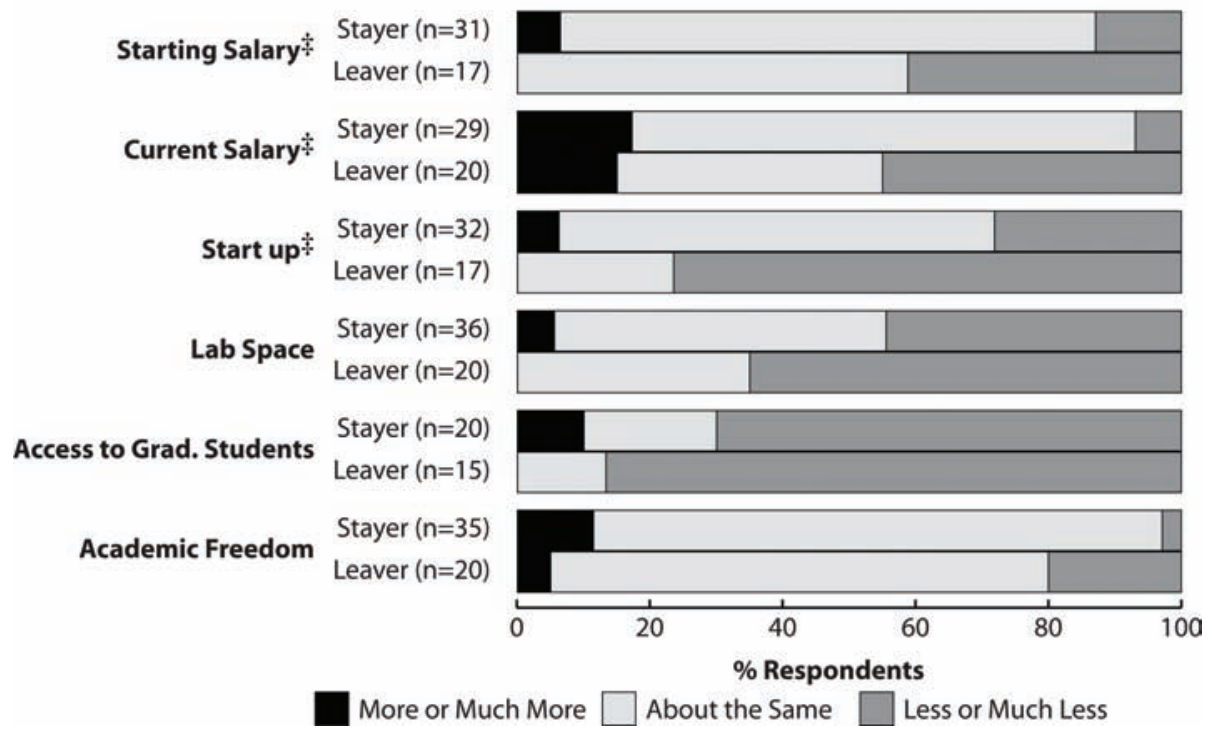

Figure 11. SFES Stayers' versus SFES Leavers' perceptions of time spent on professional activities and access to resources compared with non-SFES. (A) Perceptions of time spent on teaching, scholarship, and service relative to nonSFES disaggregated by those who are not "seriously considering leaving their current position" (Stayer) and those who are "seriously considering leaving their current position" (Leaver). (B) Perceptions of access to resources relative to non-SFES disaggregated by Leaver and Stayer. *Indicates statistically significant differences $(p<0.05)$. ${ }^{\ddagger}$ Indicates statistically significant differences $(p<0.05)$ when comparing the joined category of "more or much more" and "about the same" with "less or much less." scholarly activities in their departments as well as a perception of greater service expectations as compared with nonSFES. More specifically, higher proportions of Biology SFES perceived misunderstandings between themselves and their administrators regarding service expectations and activities, as compared with SFES from other disciplines. Higher proportions of SFES were considering leaving their positions if they did not feel they were doing what they were hired to do, and as reasons they stated science education was not valued, understood, or supported by their university. One possible explanation for these frustrations is that departmental administrators and non-SFES may conflate SFES scholarly activities and service activities due to a lack of understanding of science education efforts. SFES advise new SFES to obtain clear expectations, educate colleagues about the nature of SFES work, and make sure that the department and college value and reward science education activities. SFES advice was consistent with a general lack of specificity of SFES roles and reasons for their hiring.

Results from this study suggest that departments interested in establishing SFES positions need to have explicit conversations and written expectations about the nature of SFES positions (Bush et al., 2006). Involvement in all science education arenas- $\mathrm{K}-12$ science education, undergraduate science education, and science education researchmay extend beyond the formal training and capacity of any individual SFES, yet SFES may be looked to as experts in all these arenas. Departments could choose to hire SFES to specialize in a particular arena (e.g., K-12 science teacher preparation or discipline-based science education research), depending on local departmental needs. Alternatively, departments may choose to hire an SFES just as they would any other faculty member, with the expectation that the SFES's scholarly activities would be of their own choice and generally in one of the arenas of science education. Finally, departments may need to articulate explicitly what will constitute SFES scholarly activities-whether these will be focused in basic science research, science education research, or bothand how SFES scholarly activities are distinct from service activities. Clarity and agreement among SFES, their administrators, and their non-SFES colleagues about the purpose of the position within the department appears to be critical.

\section{SFES Formal Professional Training More Extensive in Science Than in Science Education}

Broadly speaking, CSU SFES appear to be similar to other university science faculty in their basic science training. Nearly $90 \%$ completed science PhDs, and nearly $40 \%$ had a postdoctoral position in science. Although more SFES who were hired into these positions have formal training in science education compared with SFES who have transitioned into an SFES role, formal training in science education is minimal for both groups (Bush et al., 2008). These data are consistent with the idea that science departments may prefer to hire individuals trained as basic research scientists into their departments to address science education issues. Because a majority of CSU SFES are working in multiple arenas of science education, they may be engaged in a wide variety of professional activities that require knowledge and skills that 


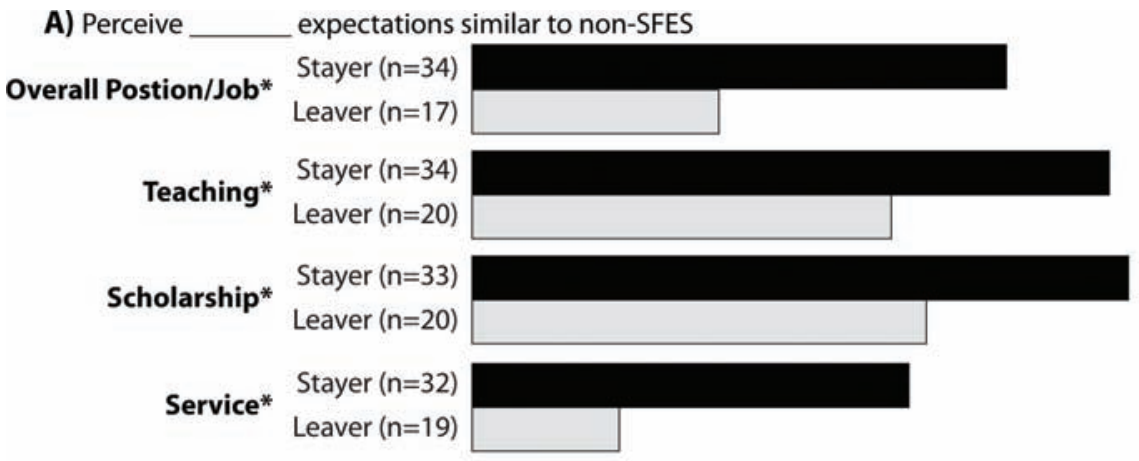

B) Fulfilled by

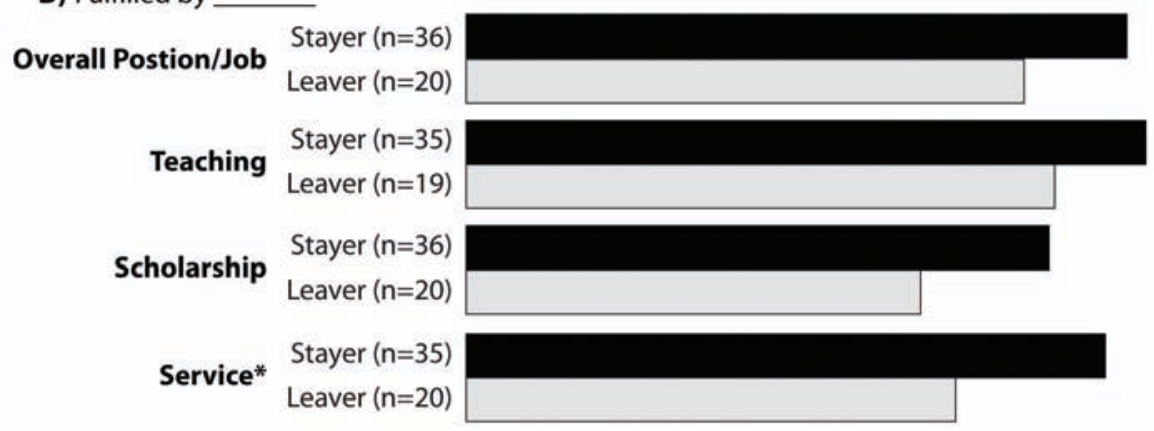

C) Doing hired to do

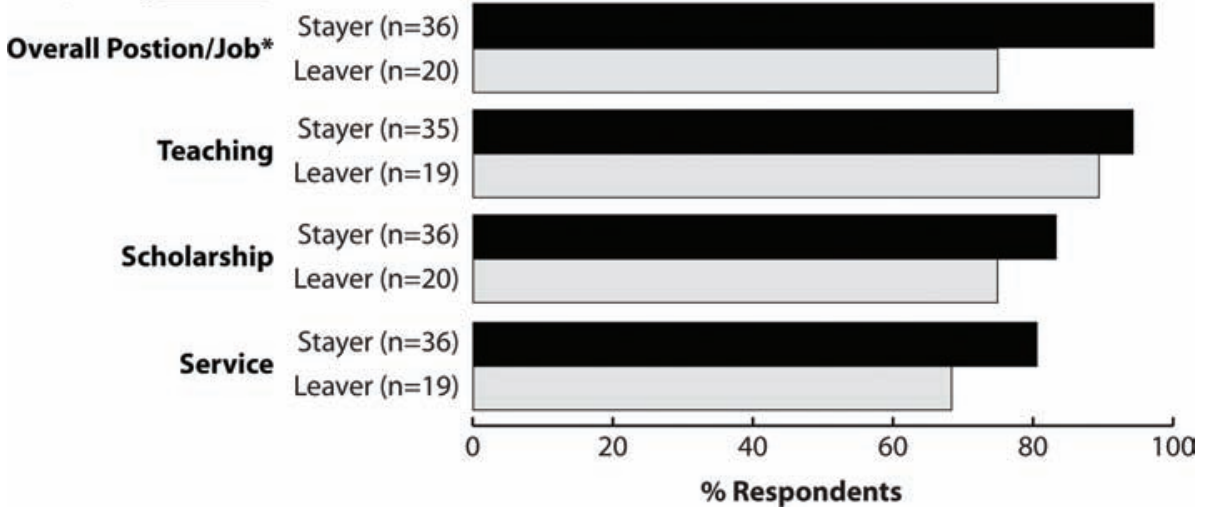

Figure 12. SFES Stayers' versus SFES Leavers' position expectations and professional fulfillment. Perceptions of professional expectations relative to nonSFES (A), fulfillment by professional activities (B), and engagement in professional activities hired to do (C) disaggregated by those who are not "seriously considering leaving their current position" (Stayer) and those who are "seriously considering leaving their current position" (Leaver). *Indicates statistically significant differences $(p<0.05)$. extend beyond those acquired in their formal academic training. Whereas many science faculty pursue professional activities outside their original area of training, SFES may differ in that they are more likely to be working in areas traditionally considered domains of social science. Although CSU SFES as a group reported high levels of fulfillment in their position and overall job activities, scholarly activities had the lowest proportion (ca. $75 \%$ ) of reported fulfillment. Potentially, SFES may find that their basic science training is inadequate for them to engage in multiple arenas of science education. At a minimum, SFES working in new areas outside of their formal training may need additional time to develop new

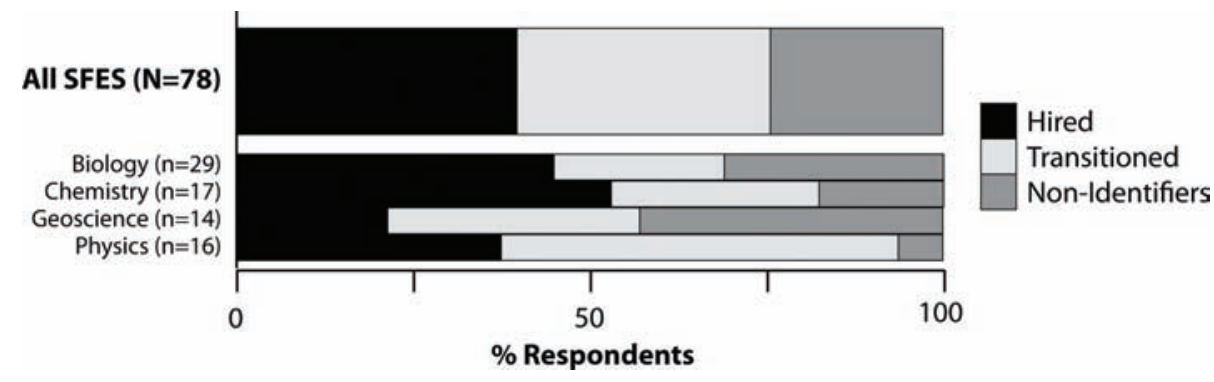

Figure 13. Pathways to SFES positions. Percentages of respondents who were hired into SFES positions, transitioned into SFES positions, or did not self identify as SFES for all respondents and disaggregated by science discipline. 
Table 3. Reasons offered for seriously considering leaving current SFES position in response to the following question: "What are the primary reasons you are seriously considering leaving?" $(n=20)$

\begin{tabular}{l} 
Category \\
\hline Science education is not \\
supported, valued, or \\
understood by department \\
and/or university \\
Overworked, burned out, and \\
unappreciated
\end{tabular}

Professional values are not aligned with department and/or university

I am not doing what I want to be doing

Salary is too low

Teaching load is too high

Lack of resources to support scholarly activities in science education

Service load is too high
- Lack of any real support from the college or university for science education. Sample quotes

- Lack of understanding about what science education is and its value among the non-SFES faculty in my department.

- Lack of understanding of SFES research and how to evaluate it.

- I feel burned out.

- I'm underpaid and overworked.

- I see new faculty who are only rewarded for traditional research and who care very little about educating students.

- Anyone who does not fit this very traditional research mold is a second-class citizen.

- There is a lack of acknowledgment for hard work.

- I struggle coping with the stress.

- My professional activities are not valued by my colleagues.

- I am not sure that my department and the CSU have the values that I thought I saw when I started this job.

- In networking with other SFES faculty, I realize that there are more problems in this field than I would have as a scientist so the choices are to leave the field or the CSU system since what I do is not valued on any level.

- I am not spending my time how I want to spend it.

- I am unhappy with the quantity of work I am expected to do and the nature of much of this work.

- When I was hired, it was made explicit that I would be able to choose research areas, including scholarship of teaching. This was a lie.

- Salary is too low and cost of living here is too high.

- Poor salary, high housing costs.

- The financial support provided through the CSU system as an Associate Professor combined with the high cost of living in urban southern California led me to consider alternate positions.

- How can you have scholarly activity with a 12-unit teaching load? The CSU has outrageous teaching loads as compared with University of California and private institutions.

- The teaching expectations at my university are too high (24 units/year.)

- I have no problem mixing service with scholarly activity, but without a graduate level program that I can connect with, there is not much that is available in the way of scholarly activity grants available.

- They take a "bean counting" approach to evaluate your research program, plus personnel committee usually does not have the background to evaluate education research.

- This position is all service, which is not what I wanted, nor signed up for.

- Although I am somehow juggling both, I do not feel that it is appropriate to expect me to be heavily involved in the teacher preparation activities-for which I have had zero training - and to build from the ground up an education research program.

- Because I have somewhat more breadth in my training than a classical scientist, I am over-burdened with service expectations re: teacher prep, student care and recruitment, evaluation, etc.

- I am on an administrative track and, if I decide to move up, I will likely have to move on. - Quality of life issues in my geographic area.

- I'm retiring. knowledge, skills, and expertise required for their SFES responsibilities. In addition, SFES who are trained in one arena (e.g., K-12 teacher development) may find that they are expected to work in a different arena (e.g., science education research) as the focus of their scholarly activities. Alignment between SFES professional training and job activities, particularly in the area of scholarship, may contribute to higher levels of job fulfillment.

The currently varied nature of SFES positions and the relatively traditional scientific training of those who occupy these positions may suggest a need for formal academic training pathways to prepare individuals for SFES positions. Opportunities for formal science education training vary across sci- ence disciplines and are not systematically or consistently available for those who also have formal science training. Although doctoral training programs do exist in chemistry education and physics education, they are still uncommon. In the areas of biology education and geoscience education, formalized doctoral training programs are quite rare. One promising approach to providing training pathways to SFES positions is postdoctoral fellowship opportunities in science education within science departments (Wieman, 2009). Current postdoctoral opportunities in science education, however, appear to focus primarily on preparing future SFES for roles in undergraduate science education reform and disciplinebased science education research with few opportunities to 
Table 4. Advice offered to beginning SFES in response to the following question: "What are the three most important pieces of advice you would offer to a beginning Science Faculty with an Education Specialty?" $(n=50)$

Category department and college

Find colleagues, mentors, and advocates

Obtain funding and publish your work

Reduce your commitments and learn to say no

Inform, educate, and highlight your efforts among your faculty colleagues and administrators

Have a thick skin, remain confident, and stay passionate about your work

Make sure department and college value and reward science education activities

Expect to be treated like non-SFES faculty

Have a clear vision of and follow your professional interests
- Go over and/or negotiate the RTP requirements for your position with both your Dean Sample quotes and your Department Chair in the same room, including how you will be supported to accomplish those requirements.

- Clear expectations, clear expectations, clear expectations.

- Know all the expectations your department and college have for your position in terms of service and research/professional development.

- Make sure that the department fully supports the position by writing its personnel document to align with scholarly activities that SFES perform.

- Establish a network of colleagues within and outside the department, for research support (collaborations) and for personal/professional support.

- Ask SFES at your institution and outside your institution for insight, advice, mentoring, and collaborations.

- It is extremely valuable to have senior faculty on your campus with whom you work, who will publicly state the value of the educational work, which you perform. They are your advocates when there is doubt among your peers.

- Be sure there is at least one other science education specialist in your department or another science department.

- Apply for grants, big and small, often! Money talks and will buy you lots of cultural currency in the university.

- Develop innovative approaches to science education that involve students and can be published.

- Apply for external funding and contribute to the literature base.

- Aggressively pursue external funding for your scholarly activities so SFES can be as productive as possible during early years in the position.

- Avoid over-committing to departmental or university service.

- Limit what you take on, even if other people refuse to do the work.

- Know how and when to say no or have someone mentoring you who can give you hints.

- Protect your time.

- The world won't fall apart if you don't do everything.

- Take advantage of every opportunity to educate your colleagues about what you do.

- Be good at PR on your service work... let everyone know precisely all that you do.

- Toot your own horn: publicize your achievements widely and loudly.

- Be confident that your expertise is valued even if it is not obvious.

- Some science faculty even have a hard time valuing plants.

- Be prepared to be underappreciated/misunderstood by your colleagues....(have) a thick skin and a warm wit.

- Humor and patience will win over more individuals than aggression and frustration.

- Make sure that the Department will appreciate science education research on an equal footing with scientific research.

- Be sure the department and college do value education research

- Request a reduced teaching load, travel funds and a comparable start-up package as non-SFES faculty.

- Be sure you have the same opportunities for internal support for scholarship as non-SFES.

- Make sure that the "assigned or expected" duties are in line with everyone else within the department.

- Don't get cornered into doing things that non-SFES faculty would not be expected to do.

- When things go to hell, remember the passion that brought you here and focus on that aspect of your work.

- Be strong! You are the future of science in the CSU!

- Have a vision of what you're trying to do and why you took this position.

- Figure out the things that are important and effective to do.

- More likely than not you will define your position. Define success you can live with.

- Be sure your research is driven by your interests, not totally by departmental needs. specialize in K-12 science education efforts (Bush et al., 2010). In addition, it is not yet clear whether individuals completing these types of postdoctoral training will be hired as full members of a science department, that is, full-time, tenure-track faculty, or as academic specialists within the department, such as lecturers and/or curriculum coordinators. Expecta- tions for SFES to be full faculty members and/or involved in multiple arenas of science education may be supported by the development of a greater variety of training pathways at the graduate, postdoctoral, and even faculty levels.

Furthermore, the multidisciplinary nature of SFES work suggests that successful SFES training pathways may need 
to convene experts and mentors for future SFES from a variety of disciplinary fields beyond the scientific disciplines, including individuals who have occupied SFES positions themselves. Existing programs with the potential to train future SFES appear to have been developed primarily by traditionally trained scientists and with little to no influence from social scientists, science education researchers, or individuals with expertise in teacher preparation and $\mathrm{K}-12$ education (Wieman, 2009). The establishment of multidisciplinary SFES training pathways may prove to be an important approach in sustaining the SFES model for building expertise and effective efforts in science education within college and university science departments.

\section{Reasons Offered for Taking an SFES Position and Considerations about Leaving}

This study portrays the majority of CSU SFES as individuals who are enthusiastic about their position. CSU SFES most often expressed that interest in science education-in the arenas of K-12 science education, undergraduate science education, and/or science education research-was the reason they originally took an SFES position. Beyond this, the motivating factors for individuals to take an SFES position did not appear to be specific to the nature of SFES work. In addition, CSU SFES report that they stay in their current positions because of the challenge, freedom, and flexibility of their jobs, as well as because of the positive relationships they have with colleagues, collaborators, and students. Importantly, many CSU SFES perceive that they are making a difference in science education.

Strikingly and despite these motivations, almost $40 \%$ of CSU SFES expressed that they were seriously considering leaving their current positions, but not the field. Because this study was an initial description of the SFES phenomenon, the uniqueness of SFES considerations of leaving compared with non-SFES is unclear. However, there were numerous statistically significant differences between those SFES who were considering leaving and those who were not. Data presented here show that SFES who were considering leaving have perceptions of unequal treatment compared with nonSFES colleagues. In addition, the most common reason offered by SFES considering leaving was that their work in science education was not supported, valued, and/or understood. CSU SFES perceived differential access to resources to support their scholarly activities compared with non-SFES, especially in terms of start-up funds, laboratory space, and access to graduate students and existing academic infrastructure, such as course and degree offerings in their field. In addition, the majority of SFES perceived that they spend more time on service activities than non-SFES, and high service loads were reported explicitly as a reason for seriously considering leaving. These perceptions of less scholarly support and elevated service were more prevalent among those CSU SFES who were seriously considering leaving. Some also reported a misalignment between their professional values and those of their colleagues and a more general feeling of being overworked, burned out, and unappreciated in their institutions.

To capitalize on the value that SFES could add to science departments, the structure and purpose of these positions need to be explicitly articulated and the material, intellec- tual, and time resources allocated be sufficient to meet SFES responsibilities. In particular, attention by administrators to SFES perceptions of inequality compared with non-SFES, especially in terms of access to resources to support scholarly activities and service expectations, may be key to SFES satisfaction and retention. For example, some SFES may need time to devise and implement an academic infrastructure to support training of students to participate in their scholarly activities. Other SFES may need time to gain expertise in a science education arena that is new to them. Finally, greater clarity about SFES job expectations and more and varied opportunities for SFES training, as described above, may also contribute to reducing potential SFES dissatisfaction and increasing SFES retention.

\section{Need for National Study on the Nature and Impact of the SFES Phenomenon}

Although the results of this CSU SFES research study are informative, a national study of the SFES phenomenon would provide a stronger basis for understanding this model for transforming science education. Some of the results presented here may represent the general SFES phenomenon, whereas others may only be characteristic of the CSU system. As an example, CSU SFES positions are not primarily teaching positions, but SFES positions at other types of academic institutions may be. Some may consider SFES positions as primarily discipline-based science education research positions, similar to many physics education research groups within physics departments, but CSU SFES positions are not. Rather, CSU SFES appear to be heavily involved in $\mathrm{K}-12$ teacher preparation, which may be specific to the CSU and its primary role in California teacher preparation. To clarify the extent to which these findings about CSU SFES are predictive of the SFES phenomenon more generally, a national study of SFES across multiple types of academic institutions is essential. In addition, a national study of larger numbers of SFES would provide sufficient statistical power to investigate disciplinespecific differences, if any, among SFES. Finally, a national study of the characteristics of SFES, their institutional contexts, and their perceived impact could shed light on the extent to which SFES are a transient phenomenon or represent a larger jurisdictional shift of science education into university science departments.

\section{CONCLUSIONS}

Our research study investigated the nature of the SFES phenomenon in the United States. We found that CSU SFES were engaged in the three key arenas of science education (K-12 science education, undergraduate science education, and discipline-based science education research), as well as basic science research. As such, CSU SFES appeared to be well-positioned to have an impact on science education from within science departments. However, there appeared to be a lack of clarity and agreement about the purpose of these CSU SFES positions, which could hinder both the effectiveness of SFES efforts and the growth of the SFES phenomenon. In addition, formal training in science education among SFES was limited, suggesting a need for formal training opportunities in science education for future and current SFES. Whereas over $75 \%$ of SFES were fulfilled by their teaching, 
scholarship, and service, our results revealed that almost $40 \%$ of CSU SFES were seriously considering leaving their positions but not the field. A key statistically significant difference between those seriously considering leaving and those not seriously considering leaving was the perception of inequitable access to resources as compared with non-SFES. Our data suggest that science departments may benefit from explicit discussions about the role of SFES and strategies for supporting their professional activities. Our research findings have the potential to inform a national study of SFES, promote a greater SFES community, and strengthen the conversation among science education stakeholders about the purposes of SFES positions and strategies to maximize SFES impact.

\section{ACKNOWLEDGMENTS}

We thank the CSU Chancellor's Office for funding and Dr. Beverly Marcum (CSU Chico) and Dr. Ed Walton (Cal Poly Pomona) for organizing the 2006 CSU-wide Science Education Colloquium in Pomona, CA, where the authors of this study initially met. We also thank the Deans of Colleges of Science for their assistance in identifying CSU SFES. Funding for this research was generously provided by the following CSU campus administrators: Dean Phil Bailey (Cal Poly San Luis Obispo), Dean Gary Novak (CSU Los Angeles), Interim Dean Jane Bruner (CSU Stanislaus), Dean Stanley Malloy (San Diego State University), and Dean Sheldon Axler (San Francisco State University). S.B. would like to acknowledge the Cal Poly Center for Excellence in Science and Math Education for coordination of funding. N.P. was supported by the NSF Independent Research/Development Program while on leave from CSU Fullerton in 2007 to serve as Program Director in the Division of Undergraduate Education (EHR/DUE) of the NSF; any opinion, findings, and conclusions or recommendations expressed in this material are those of the author and do not necessarily reflect the views of the NSF. We thank Dean Steve Murray (CSU Fullerton) for providing space to meet, Dr. Barbara Gonzalez (CSU Fullerton) for use of her laboratory, and SFES outside the CSU for their participation in validation of the survey instrument. Finally, we thank the CSU SFES who participated in this research and our families for their ongoing patience and support.

\section{REFERENCES}

Alberts B (1994). Scientists Have Important Roles, Responsibilities in Future of Science Education, National Academy of Science's Resources for Involving Scientists in Education www.aps.org/units/fed/newsletters/nov94/alberts.html (accessed 29 December 2010).

American Association for the Advancement of Science (1993). Benchmarks for Science Literacy (Project 2061). New York: Oxford University Press. www.project2061.org/publications/bsl (accessed 29 December 2010)

American Physical Society (1999). APS Statement on Research in Physics Education. www.aps.org/publications/apsnews/ 199908/statements.cfm (accessed 10 June 2008).

Bower JM (2001). Scientists and science education reform: myths, methods, and madness. In: Resources for Involving Scientists in Education (RISE). [Online] National Academies of Science. www.nas.edu/rise/backg2a.htm (accessed 10 November 2008).

Bush SD, Pelaez NI, Rudd JA, Stevens MT, Williams KS, Allen DE, Tanner KD (2006). On hiring science faculty with education specialties for your science (not education) department. CBE Life Sci Educ $5,297-305$.
Bush SD, Pelaez NJ, Rudd JA, Stevens MT, Tanner KD, Williams KS (2008). Science faculty with education specialties. Science 322, 17951796.

Bush SD, Pelaez NJ, Rudd JA, Stevens MT, Tanner KD, Williams KS, Wood WB (2010). A role for postdocs in undergraduate education. Science $327,522-523$.

California State University (2006). System-wide Science Education Colloquium, 5-6 May 2006.

Dolan E, Tanner KD (2005). Points of view: moving from outreach to partnership: striving for articulation and reform across the K-20+ science education continuum. Cell Biol Educ 4(1), 28-37.

Glaser BG, Strauss AL (1967). The Discovery of Grounded Theory, Chicago: Aldine Publishing Company.

McWilliam E, Poronnik P, Taylor PG (2008). Re-designing science pedagogy: reversing the flight from science. J Sci Educ Technol 17, 226-235.

National Academy of Sciences (NAS) (2005). Workshop for Discipline-based Science Education Research. www7 .nationalacademies.org / cfe /STEM_Disciplines_Agenda.html (accessed 10 June 2008)

NAS, National Academy of Engineering, and Institute of Medicine of the National Academies (2007). Rising Above the Gathering Storm: Energizing and Employing America for a Brighter Economic Future, Washington, DC: National Academies Press (http://books.nap.edu/catalog/11463.html).

National Research Council (2007). Taking Science to School: Learning and Teaching Science in Grades K-8, ed. RA Duschl, HA Schweingruber, and AW Shouse, Washington, DC: National Academies Press.

National Science Board (2007). A National Action Plan for Addressing the Critical Needs of the U.S. Science, Technology, Engineering, and Mathematics Education System. www.nsf.gov/nsb/ stem/index.jsp (accessed 10 June 2008).

National Science Foundation (1996). Shaping the Future: New Expectations for Undergraduate Education in Science, Mathematics, Engineering, and Technology. www.nsf.gov/pubs/ stis1996/nsf96139/nsf96139.txt (accessed 21 July 2010).

Pelaez NJ, Gonzalez BL (2002). Sharing science: characteristics of effective scientist-teacher interactions. Adv Physiol Educ 26(3), 158167

Plackett RL (1983). Karl Pearson and the chi-squared test. Int Stat Rev 51(1), 59-72.

Sunal DW, Hodges J, Sunal CS, Whitaker KW, Freeman M, Edwards L, Johnston RA, Odell M (2001). Teaching science in higher education: faculty professional development and barriers to change. School Sci Math 101(5), 246-257.

University of California Office of the President (2007). California Master Plan for Higher Education. http://ucfuture .universityofcalifornia.edu / documents / ca_masterplan_summary .pdf (accessed 10 June 2008).

U.S. Congress House of Representatives (2007). America COMPETES Act (H.R. 2272). http://science.house.gov/legislation/leg _highlights_detail.aspx?NewsID=1938 (accessed 10 June 2008).

Walczyk JJ, Ramsey LL, Zha P (2007). Obstacles to instructional innovation according to college science and mathematics faculty. J Res Sci Teach 44(1), 85-106.

Wieman C (2009). Galvanizing science departments. Science 325(5945), 1181

Woodin T, Carter C, Fletcher L (2010). Vision and change in biology undergraduate education, a call for action-initial responses. CBE Life Sci Educ 9(1), 71-73.

Yates F (1934). Contingency table involving small numbers and the $\chi^{2}$ test. Suppl J R Stat Soc 1(2), 217-235. 